\title{
Anti-cancer effect of doxorubicin is mediated by downregulation of HMG-Co A reductase via inhibition of EGFR/Src pathway
}

\author{
Un-Jung Yun ${ }^{1} \cdot$ Ji-Hye Lee ${ }^{1} \cdot$ Jaegal Shim ${ }^{1} \cdot$ Kyungsil Yoon ${ }^{1} \cdot$ Sung-Ho Goh ${ }^{2}$ Eun Hee $\mathrm{Yi}^{3} \cdot$ Sang-Kyu $\mathrm{Ye}^{3}$. \\ Jae-Seon Lee ${ }^{4} \cdot$ Hyunji Lee ${ }^{5}$ Jongsun Park $\mathbb{1}^{5} \cdot$ In Hye Lee $\mathbb{C}^{6} \cdot$ Yong-Nyun Kim $^{1}$
}

Received: 16 May 2018 / Revised: 30 November 2018 / Accepted: 19 December 2018 / Published online: 30 January 2019

(c) United States \& Canadian Academy of Pathology 2019

\begin{abstract}
Doxorubicin is a widely used DNA damage-inducing anti-cancer drug. However, its use is limited by its dose-dependent side effects, such as cardiac toxicity. Cholesterol-lowering statin drugs increase the efficacy of some anti-cancer drugs. Cholesterol is important for cell growth and a critical component of lipid rafts, which are plasma membrane microdomains important for cell signaling. 3-hydroxy-3-methylglutaryl coenzyme A (HMG-CoA) reductase (HMG-CR) is a critical enzyme in cholesterol synthesis. Here, we show that doxorubicin downregulated HMG-CR protein levels and thus reduced levels of cholesterol and lipid rafts. Cholesterol addition attenuated doxorubicin-induced cell death, and cholesterol depletion enhanced it. Reduction of HMG-CR activity by simvastatin, a statin that acts as an HMG-CR inhibitor, or by siRNAmediated HMG-CR knockdown enhanced doxorubicin cytotoxicity. Doxorubicin-induced HMG-CR downregulation was associated with inactivation of the EGFR-Src pathway. Furthermore, a high-cholesterol-diet attenuated the anti-cancer activity of doxorubicin in a tumor xenograft mouse model. In a multivulva model of Caenorhabditis elegans expressing an active-EGFR mutant, doxorubicin decreased hyperplasia more efficiently in the absence than in the presence of cholesterol. These data indicate that EGFR/Src/HMG-CR is a new pathway mediating doxorubicin-induced cell death and that cholesterol control could be combined with doxorubicin treatment to enhance efficacy and thus reduce side effects.
\end{abstract}

\section{Introduction}

Although anti-tumor drugs doxorubicin and daunorubicin have been widely used to treat cancers including breast, lung, thyroid, and hematologic cancers, their use is limited by dose-dependent side effects, such as cardiac toxicity

These authors contributed equally: Un-Jung Yun, Ji-Hye Lee

Supplementary information The online version of this article (https:// doi.org/10.1038/s41374-019-0193-1) contains supplementary material, which is available to authorized users.

In Hye Lee

lih3026@ewha.ac.kr

$\triangle$ Yong-Nyun Kim

ynk@ncc.re.kr

1 Comparative Biomedicine Research Branch, Division of Translational Science, National Cancer Center, Goyang, Korea

2 Therapeutic Target Discovery Branch, Division of Precision Medicine, National Cancer Center, Goyang, Korea
$[1,2]$. This clinical problem can be overcome by developing treatment protocols that increase the drug efficiency, allowing a reduction of dosage [2]. In vitro, statins are known to enhance the effects of doxorubicin in cell lines from rhabdomyosarcoma, breast cancer, ovarian cancer, and osteosarcoma [3-6]. Statins inhibit HMG-CR, which is the rate-controlling enzyme of the mevalonate pathway in cholesterol synthesis [7]. Statins have shown beneficial effects in combination with other anti-cancer drugs in clinical studies. For example, statins sensitize human cancer cells to genotoxic anti-cancer drugs, such as cisplatin, 5fluorouracil, and etoposide [4, 6, 8]. Pravastatin prolongs

3 Department of Pharmacology, College of Medicine, Seoul National University, Seoul, Korea

4 Department of Molecular medicine, College of Medicine, Inha University, Incheon, Korea

5 Department of Pharmacology and Medical Science, Metabolic Syndrome and Cell Signaling Laboratory, Institute for Cancer Research, College of Medicine, Chungnam National University, Daejeon, Korea

6 Department of Life Science, Ewha Womans University, Seoul, Korea 
the survival of patients with hepatocellular carcinoma when combined with 5-fluorouracil [9]. Fluvastatin in combination with thalidomide, carboplatin, and vincristine significantly reduces the volume of brain stem tumors [10]. Together, these studies indicate that cholesterol-lowering drugs exert-positive effects when combined with various anti-cancer drugs, although the mechanisms involved in these synergistic effects are not well defined.

Cholesterol is an essential lipid for cell membrane biogenesis as well as cell proliferation and differentiation [11]. Cholesterol is also a critical component of lipid rafts, which are sphingolipid-enriched microdomains of the plasma membrane [12]. Lipid rafts contain various signaling molecules-including epidermal growth factor receptor (EGFR), Ras, FAS/CD95, and Wnt-and thus the integrity of these microdomains is critical for cell signaling in the regulation of cell proliferation, motility, and survival [12]. The depletion of cholesterol from the plasma membrane disrupts lipid rafts, which induces inappropriate cellular signaling, leading to deregulation of cellular function and sometimes cell death $[12,13]$. Cholesterol accumulation has been reported in several solid tumors [14], and cholesterol levels are higher in breast and prostate cancer cells than their normal counterpart cells $[11,15]$. This cholesterol accumulation in cancer cells might expand lipid rafts and thus promote cell proliferation and survival [16]. Elevated cholesterol levels are associated with cancer cell growth in vitro [13] and hyperlipidemia accelerates tumor growth and metastasis in mice [17], suggesting that cholesterol is associated with cancer progression. Moreover, cohort studies indicated that reduction of cholesterol with statins decreases all-cause mortality in prostate cancer patients [18, 19]. These data suggest that the regulation of cholesterol levels is important for cancer control.

In this study, we demonstrate that doxorubicin, a genotoxic anti-cancer drug, exerts its anti-cancer effect via modulation of cholesterol synthesis. Doxorubicin lowers cholesterol levels and thus induces lipid raft redistribution in A431 human epidermoid carcinoma cells via decreased HMG-CR expression, which is mediated by the EGFR-Src pathway. Addition of cholesterol attenuated the anti-cancer effects of doxorubicin both in vitro and in vivo. These results indicate that control of cholesterol levels may serve as a potential adjuvant therapy to maximize the anti-cancer effects of doxorubicin.

\section{Materials and methods}

\section{Materials}

Alexa Fluor 488-conjugated cholera toxin subunit B (CTxB) was obtained from Molecular Probes (Eugene, OR, USA).
The anti-EGFR, anti-Src, anti-HMG-CR, anti-sterolregulatory element-binding protein (SREBP)-1, and horseradish peroxidase (HRP)-conjugated goat anti-mouse and anti-rabbit antibodies were purchased from Santa Cruz Biotechnology (Santa Cruz, CA, USA). Anti-phospho-Src and anti-fatty acid synthase (FASN) antibodies were obtained from Cell Signaling Technology (Beverly, MA, USA). Antiphospho-EGFR (1068) was obtained from Invitrogen/Life technologies (Carlsbad, CA, USA). Doxorubicin, methyl- $\beta$ cyclodextrin (M $\beta C D)$, water-soluble cholesterol, and simvastatin were purchased from Sigma-Aldrich (St. Louis, MO, USA). Mevalonolactone, which turns to mevalonate [20], was purchased from Sigma-Aldrich.

\section{Cell culture}

Human epidermoid carcinoma cell line A431 and prostate cancer cell lines PC3 and DU145 were obtained from the American Type Culture Collection (ATCC; Rockville, MD, USA). Human ovarian carcinoma cell line OVCAR8 and its multiple anti-cancer drug-resistant derivative cell line NCI/ ADR-RES were obtained from the National Cancer Institute (Rockville, MD, USA). A431 cells were grown in DMEM (Hyclone, Logan, UT, USA) supplemented with 10\% FBS (Hyclone). OVCAR8, NCI/ADR-RES, PC3, and DU145 cells were grown in RPMI supplemented with $10 \%$ FBS, 100 units $/ \mathrm{ml}$ penicillin, $100 \mu \mathrm{g} / \mathrm{ml}$ streptomycin, and 0.25 $\mu \mathrm{g} / \mathrm{ml}$ amphotericin B (Antibiotic-Antimycotic, Gibco Laboratories Co.; Grand Island, NY, USA) at $37^{\circ} \mathrm{C}$ in a humidified atmosphere containing $5 \% \mathrm{CO}_{2}$.

\section{Drug treatment}

Cells were grown to $\sim 70 \%$ confluence and then serumstarved in DMEM or RPMI containing $0.1 \%$ bovine serum albumin (BSA) prior to treatment. Cells were treated with the indicated concentrations of reagents in the same media.

\section{Plasmid and siRNA transfection}

Cells were transiently transfected with active-Src plasmid [21] or vector for control using metapectene pro (Biontex laboratories, Martinsried, Germany) as described by the manufacturer. Small interfering RNA (siRNA) for knockdown of HMG-CR (1069722) and for a negative control (SN-1003) were obtained from Bioneer (Daejeon, Korea). Cells were transfected with siRNA duplexes using lipofectamine RNAiMAX reagent (Invitrogen) as described by the manufacturer.

\section{Cell proliferation assay}

Cell growth was determined with the CellTiter 96 AQueous Non-Radioactive Cell Proliferation Assay kit using 3-(4,5- 
dimethylthiazol-2-yl)-5-(3-carboxyme-thoxyphenyl)-2-(4sulfophenyl)-2H-tetrazolium (MTS; Promega, Madison, WI, USA) as described in the manufacturer's instructions. Absorbance was measured at $490 \mathrm{~nm}$ with a PowerWave HT spectrophotometer (Biotek instruments, Winooski, VT, USA).

\section{Live-cell imaging}

Immediately after drug treatment, cells were assessed by live cell imaging using Zeiss Axio Observer live cell station (Carl Zeiss Microimaging, Göttingen, Germany) and an Axion Vision camera (Axion Technologies, Houston, TX, USA). During imaging, cells were maintained on a stage heated to $37{ }^{\circ} \mathrm{C}$ under a $5 \% \mathrm{CO}_{2}$ atmosphere.

\section{Live- and dead-cell staining}

Cells were stained with ethidium homodimer- 1 and calcein $\mathrm{AM}$ for $20 \mathrm{~min}$ and then assessed using a fluorescence microscope (Carl Zeiss, Jena, Germany).

\section{Cholesterol assays}

Cells were suspended in HES buffer (20 mM HEPES, pH 7.4, $1 \mathrm{mM}$ EDTA, $255 \mathrm{mM}$ sucrose) and incubated on ice for $30 \mathrm{~min}$. Cellular cholesterol levels were measured using the Amplex ${ }^{\circledR}$ Red Cholesterol Assay Kit (Invitrogen) according to the manufacturer's instructions [22].

\section{Immunoblot analysis}

Cells were lysed with $2 \mathrm{X}$ sodium dodecyl sulphatepolyacrylamide gel electrophoresis (SDS-PAGE) lysis buffer $(20 \mathrm{mM}$ Tris, $\mathrm{pH} 8.0,2 \%$ SDS, $2 \mathrm{mM}$ dithiothreitol (DTT), $1 \mathrm{mM} \mathrm{Na} \mathrm{VO}_{4}, 2 \mathrm{mM}$ ethylenediaminetetraacetic acid (EDTA), 20\% glycerol) and sonicated. Protein extracts were immunoblotted as described previously [21].

\section{Reverse transcription quantitative PCR}

Total cellular RNA was isolated with the Trizol reagent (Invitrogen) according to the manufacturer's instructions. Then, cDNA synthesis was achieved using Maxime RT Premix kit (Intron Biotechnology, Seoul, Korea), and cDNA fragments were amplified with the following primer pairs: HMG-CR 5'-TACCATGTCAGGGGTACGTC-3' (forward), 5'-CAAGCCTAGAGTCATAATCAT-3' (reverse), GAPDH 5'-GACCCCTTCATTGACCTCAAC-3' (forward), and $5^{\prime}$-CTTCTCCATGGTGGTGAAGA-3' (reverse). PCR was performed using a Gradient Thermal Cycler (Biometra, Goettingen, Germany) with AccuPower PCR Premix (Bioneer). Quantitative PCR was performed on a LightCycler 96
System (Roche, Basel, Switzerland) with using Rotor-Gene SYBR Green PCR Kit (Qiagen, Hamburg, Germany). Primers for HMG-CR (P225340) and $\alpha$-tubulin (P203068) were obtained from Bioneer.

\section{Immunofluorescence analysis}

Cells were fixed with $1 \%$ paraformaldehyde in PBS at $4{ }^{\circ} \mathrm{C}$ for $20 \mathrm{~min}$, permeabilized with $0.2 \%$ Triton $\mathrm{X}-100$ in PBS for $5 \mathrm{~min}$, and then stained with Alexa Fluor 488conjugated $\mathrm{CTxB}$ for monosialotetrahexosylganglioside (GM-1) for $1 \mathrm{~h}$ at room temperature. For EGFR staining, cells were first permeabilized and blocked in 3\% BSA in PBS for $1 \mathrm{~h}$ at room temperature. Cells were then incubated with anti-EGFR antibody at $4{ }^{\circ} \mathrm{C}$ overnight, and then incubated with Alexa Fluor 488-conjugated antibody for $1 \mathrm{~h}$ at room temperature. For nucleus staining, cells were incubated with Hoechst 33342 in PBS. Cells were examined using confocal microscopy (Carl Zeiss).

\section{Annexin V/PI staining}

For detection of apoptotic cells, cells were collected and incubated with fluorescein isothiocyanate (FITC)-conjugated annexin $\mathrm{V}$ reagent and propidium iodide $(\mathrm{PI})$ according to the manufacturer's instructions for the FITC Annexin V Apoptosis Detection Kit I (BD Biosciences, San Jose, CA, USA). Cells were then analyzed using flow cytometry. The data were analyzed with Cell Quest software (BD Biosciences).

\section{Mouse tumor xenograft}

Four-week-old male BALB-c nu/nu mice (Orient Bio, Korea) were housed in filtered-air flow cabinets and manipulated using aseptic procedures. The mice were fed either a standard chow diet (altromin 1314; Altromin, Lage, Germany) or a high-cholesterol diet (D12336; Research Diets, New Brunswick, NJ, USA). A high-cholesterol diet was begun 3 days before injecting cells into the mice. A431 cells were resuspended in PBS and mixed with Matrigel (1:1, vol/vol, BD Biosciences, Bedford, MA, USA) to a final volume of $0.1 \mathrm{ml}$. Each animal was injected subcutaneously with $1 \times 10^{6}$ A431 cells. Once the tumors became palpable $\left(\sim 100 \mathrm{~mm}^{3}\right)$, the mice were assigned randomly to four groups ( $n=4$ mice per group). Doxorubicin was injected intraperitoneally twice per week into tumorbearing mice. The control group was injected with vehicle (PBS). The tumor sizes were measured with calipers, and their volumes were calculated using the following formula: tumor volume $=\left(\right.$ length $\times$ width $\left.^{2}\right) / 2$. For immunohistochemistry, tumor tissues were fixed with $10 \%$ neutral buffered formalin, paraffin-embedded, and cut at a thickness 
of $4 \mu \mathrm{m}$. Sections were dried for $1 \mathrm{~h}$ at $56^{\circ} \mathrm{C}$ and immunohistochemical staining was performed with the automated instrument Discovery XT system (Ventana medical systems, Tucson, AZ, USA) as follows: sections were deparaffinized, rehydrated, and washed with reaction buffer (Ventana medical systems), and the antigens were retrieved with heat treatment in Tris-EDTA buffer $(\mathrm{CC} 1$, Ventana medical systems) with the appropriate antibodies. This study was reviewed and approved by the Institutional Animal Care and Use Committee (IACUC) of the National Cancer Center Research Institute (NCCRI). NCCRI is an Association for Assessment and Accreditation of Laboratory Animal Care International (AAALAC International) accredited facility and abides by the Institute of Laboratory Animal Resources (ILAR) guide.

\section{Caenorhabditis elegans culture and doxorubicin treatment}

The previously generated [23] multivulva (Muv) jgIs25 strain and wild-type strain of Caenorhabditis elegans $(C$. elegans) were cultured on nematode growth medium (NGM) as previously described [24]. Drug treatment of $C$. elegans has been described previously [23]. Briefly, the synchronized L1 larvae were collected and washed three times with $\mathrm{M} 9$ buffer $\left(0.3 \% \mathrm{KH}_{2} \mathrm{PO}_{4}, 0.6 \% \mathrm{Na}_{2} \mathrm{HPO}_{4}, 0.5 \%\right.$ $\mathrm{NaCl}, 1 \mu \mathrm{M} \mathrm{MgSO}{ }_{4}$ ) and then transferred to 96 -well plates (50-150 worms per well). The final culture volume was adjusted to $100 \mu$ l with M9 buffer, either with or without cholesterol. C. elegans were then treated with $0-100 \mu \mathrm{M}$ doxorubicin for 3 days and transferred to NGM plates for 2 days of recovery. Multivulva were examined and counted under a dissecting microscope (Zeiss Stemi 2000-C, Carl Zeiss).

\section{Data analysis}

All data points represent the mean value of at least three experiments performed with triplicate samples. Statistical significance was determined by Student's $t$-test, and a $p$ value of $<0.05$ was considered to indicate statistical significance.

\section{Results}

\section{Simvastatin exerts synergistic effects on doxorubicin-induced cell death}

Several reports have shown that statins synergize with standard chemotherapeutic agents, including doxorubicin and cisplatin, and also reverse chemoresistance [4, 21]. Statins are cholesterol lowering drugs, inhibiting the rate limiting step of mevalonate pathway [3]. Simvastatin is the most commonly prescribed statin, and doxorubicin is widely used for treatment of various cancers. Here, we investigated the synergistic effect of simvastatin and doxorubicin in the human cervical epidermoid A431 cell line. Doxorubicin treatment caused a change in the cell shape from spread to rounding, which was accelerated by simvastatin co-treatment, whereas simvastatin treatment alone did not affect cell shape (Fig. 1a). Cell viability was synergistically decreased by co-treatment with doxorubicin and simvastatin (Fig. 1b). This doxorubicin-induced cell death was attenuated by the addition of exogenous cholesterol in a dose-dependent manner (Fig. 1c). Interestingly, levels of total and free cholesterol were decreased upon doxorubicin treatment in a time-dependent manner (Fig. 1d), indicating that cholesterol may play an important role in doxorubicin-induced cell death.

\section{Doxorubicin modulates lipid rafts, and cholesterol supplementation reverses lipid rafts modulation}

Cholesterol is a critical lipid component of plasma membrane microdomains known as lipid rafts [25]. Cholesterol depletion using $\mathrm{M} \beta C D$ is known to disrupt lipid raft structure, which results in lipid raft internalization [25]. Because doxorubicin treatment decreased the cellular levels of cholesterol (Fig. 1d), we predicted doxorubicin treatment might affect surface lipid raft levels. To test this possibility, we examined cell surface lipid rafts by staining for GM-1, a marker of lipid rafts. GM-1 staining was evident in the cell membrane in the control cells, but GM-1 levels were decreased and differently localized in the doxorubicintreated cells, indicating downregulation and redistribution of lipid rafts by doxorubicin treatment (Fig. 1e). These doxorubicin-induced alterations in the GM-1 staining pattern and intensity were reversed by cholesterol addition (Fig. 1e). When cells were permeabilized to stain lipid rafts both on cell surface and on the cytoplasmic side, GM-1 staining intensity was restored in the doxorubicin-treated cells if not all, suggesting that GM-1 relocalized from the surface of the cell to the cytosol (Fig. 1f).

To further examine whether cholesterol levels affect doxorubicin efficacy, cells were treated with $\mathrm{M} \beta \mathrm{CD}$ to deplete cholesterol, and compared to cells in which cholesterol was replenished following the depletion. For these experiments, we used $500 \mu \mathrm{M} \mathrm{M} \beta \mathrm{CD}$, which did not affect either cell viability or morphology (data not shown). Treatment of cells with M $\beta C D$ and doxorubicin together induced dramatic cell detachment when compared with doxorubicin alone, as observed by time-lapse microscopy (Fig. 1g); however, addition of cholesterol decreased this doxorubicin-induced detachment (Fig. 1g). In addition, a two-color fluorescence cell viability assay 
A

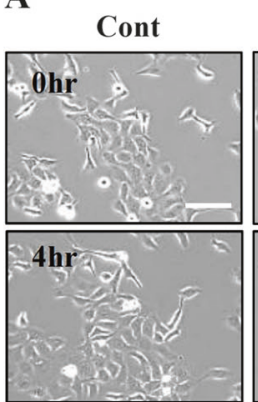

C

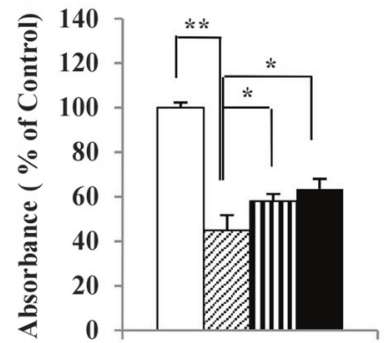

Dox $(1 \mu \mathrm{M}): \quad-\quad++$

Chol $(\mu \mathrm{M})$ : $\quad$ - $\quad$ - $\quad 50100$

E

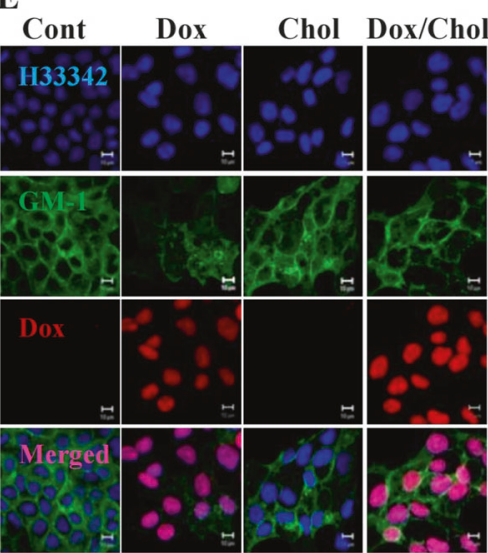

Nonpermeabilized
D

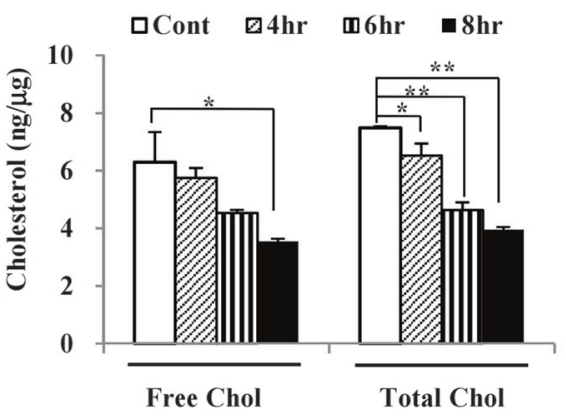

F Cont Dox Chol Dox/Chol

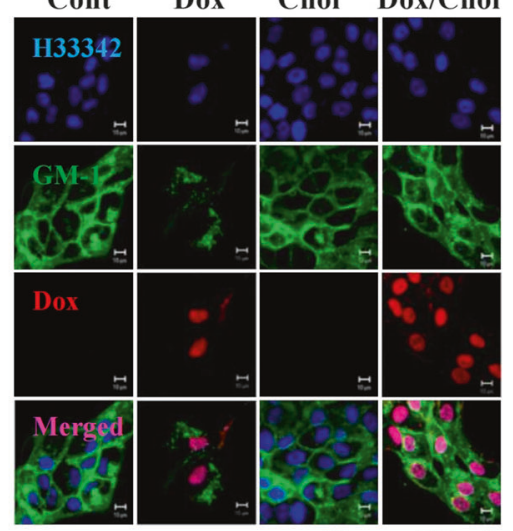

Permeabilized
B

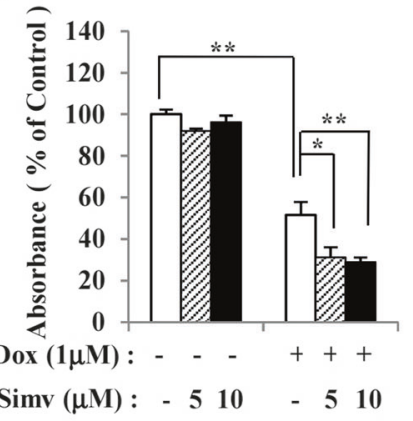

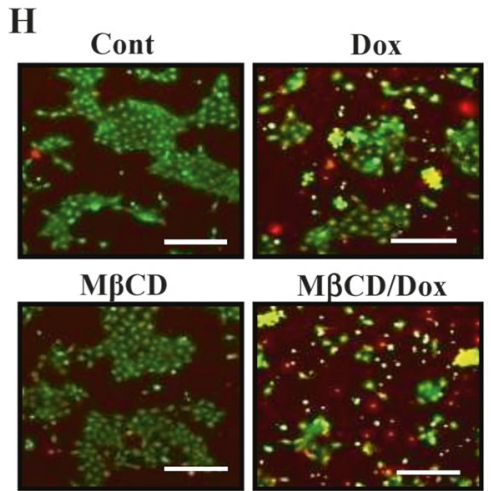
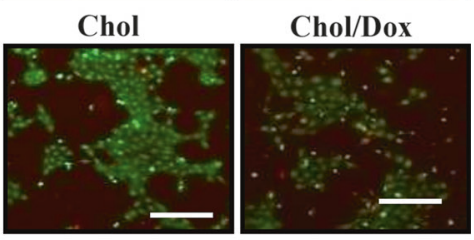

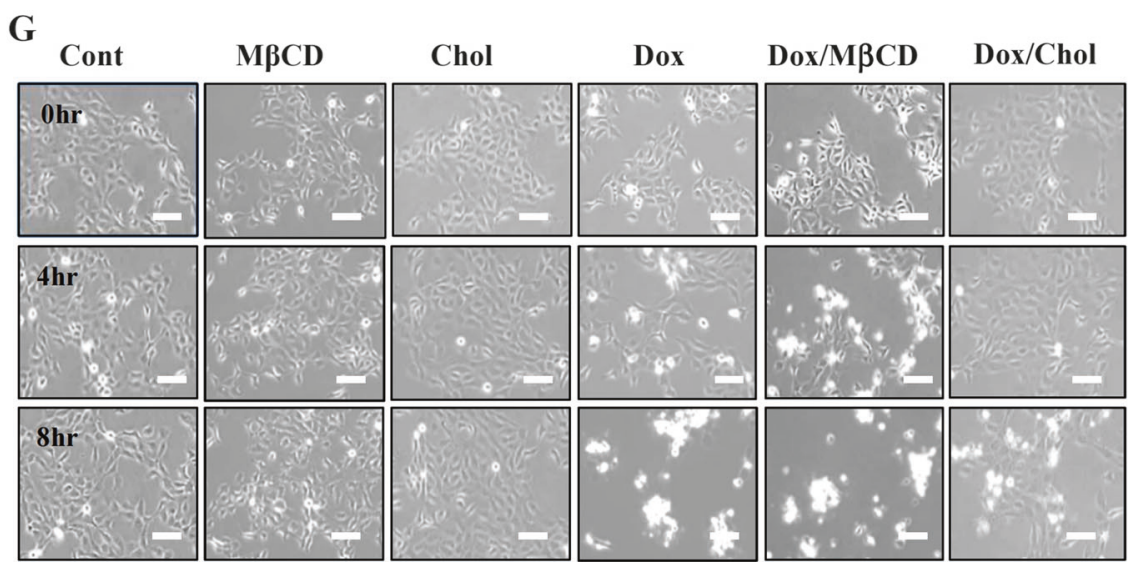


Fig. 1 Effects of cholesterol levels on doxorubicin-induced cell death. a Serum-starved A431 cells were treated with $1 \mu \mathrm{M}$ doxorubicin, $5 \mu \mathrm{M}$ simvastatin, or both $1 \mu \mathrm{M}$ doxorubicin and $5 \mu \mathrm{M}$ simvastatin for $4 \mathrm{~h}$ and time-lapse images of cells were acquired using the Zeiss Axio observer live cell station every hour. Magnification: $\times 100$, Scale bars $=100 \mu \mathrm{M}$. b Serum-starved A431 cells were treated with or without the indicated concentrations of simvastatin, $1 \mu \mathrm{M}$ doxorubicin, or both simvastatin and doxorubicin for $8 \mathrm{~h}$, and cell growth inhibition was measured using the MTS assay. c Serum-starved A431 cells were treated with $1 \mu \mathrm{M}$ doxorubicin or with cholesterol at the indicated concentrations and doxorubicin for $8 \mathrm{~h}$, and then cell growth inhibition was measured by MTS assay. d Serum-starved A431 cells were treated with $1 \mu \mathrm{M}$ doxorubicin for the indicated times. Total cholesterol and free cholesterol were measured using the Amplex Red cholesterol assay kit. e and f Serum-starved A431 cells were treated with or without $1 \mu \mathrm{M}$ doxorubicin, $100 \mu \mathrm{M}$ cholesterol, or both $1 \mu \mathrm{M}$ doxorubicin and $100 \mu \mathrm{M}$ cholesterol for $8 \mathrm{~h}$. Non-permeabilized cells e and permeabilized cells f were stained with CTxB-Alexa Fluor 488 for GM-1, a lipid raft marker, and with Hoechst 33342, a nuclear stain, and analyzed by confocal microscopy. Magnification: $\times 400$, Scale bar $=10 \mu \mathrm{M}$. g Serum-starved A431 cells were treated with $1 \mu \mathrm{M}$ doxorubicin, $500 \mu \mathrm{M} \mathrm{M} \beta \mathrm{CD}, 100 \mu \mathrm{M}$ cholesterol, both $500 \mu \mathrm{M} \mathrm{M} \beta \mathrm{CD}$ and $1 \mu \mathrm{M}$ doxorubicin, or $100 \mu \mathrm{M}$ cholesterol and $1 \mu \mathrm{M}$ doxorubicin together for $8 \mathrm{~h}$. Images were acquired using Zeiss Axio observer live cell station. Magnification: $\times 100$, Scale bars $=100 \mu$ M. h Serumstarved A431 cells were treated as in $\mathbf{g}$ and stained with calcein AM (live) and ethidium homodimer-1 (dead), and observed under the fluorescence microscopy. Magnification: $\times 50$, Scale bar $=200 \mu \mathrm{M}$. Similar results were observed in three-independent experiments

revealed that co-treatment of cells with $\mathrm{M} \beta \mathrm{CD}$ and doxorubicin enhanced cell death compared with doxorubicin treatment alone, and that replenishing cholesterol attenuated this cell death (Fig. 1h). These results support the notion that addition of cholesterol reduces the efficacy of doxorubicin.

\section{HMG-CR downregulation through the EGFR/Src pathway is critical for doxorubicin-induced cell death}

Because doxorubicin treatment decreased cellular cholesterol levels and cholesterol addition attenuated doxorubicininduced cell death (Fig. 1), we tested whether doxorubicin influences the cholesterol synthesis pathway. We examined whether the levels of proteins related to cholesterol synthesis were altered by doxorubicin in A431 cells. The SREBPs are transcription factors that are involved in regulation of lipid homeostasis. SREBP-1 activates genes involved in fatty acid synthesis, such as FASN, and SREBP-2 activates genes involved in cholesterol synthesis, such as HMG-CR. After SREBP precursors are activated via cleavage by SREBP cleavage activation protein (SCAP), activated SREBPs enter the nucleus to upregulate expression of their target genes [26]. Interestingly, doxorubicin increased the levels of the cleaved forms of SREBP1 and of SREBP-2; however, this treatment decreased HMG-CR protein and mRNA levels in a time-dependent manner, whereas FASN protein levels remained unchanged (Fig. 2a, b). Pretreatment of cells with MG132, a proteasome inhibitor, inhibited the HMG-CR downregulation induced by doxorubicin. HIF- $1 \alpha$ accumulation was used as a positive control for MG132 effects (Fig. 2c). More interestingly, downregulation of HMG-CR by specific siRNA sensitized the cells to doxorubicin effects as determined by increased PARP cleavage, an indicator of caspase 3 activation, compared with cells transfected with control siRNA (Fig. 2d). These data suggest that doxorubicin induces HMG-CR downregulation both by reducing mRNA transcription and increasing protein degradation and that this downregulation is, at least in part, responsible for doxorubicin-induced cell death.

Statins show synergistic anti-cancer effects with EGFR inhibitors [27]. Recently, the EGFR inhibitor gefitinib was reported to be effective for the treatment of cancer in highfat-diet-fed Mig- $6^{d / d}$ mice [28], indicating a possible linkage between EGFR and cholesterol. Therefore, we examined whether EGFR activity is associated with HMG-CR downregulation in doxorubicin-treated cells. Doxorubicin treatment in the absence or presence of simvastatin reduced phosphorylation of EGFR and Src, which was restored by cholesterol addition (Fig. 3a). Doxorubicin treatment also decreased EGFR levels, which also recovered upon addition of cholesterol, whereas Src levels remained unchanged. HMG-CR was downregulated by cholesterol (negative feedback), but upregulated by simvastatin (positive feedback) (Fig. 3a and Suppl. Figure 1A). When cells were stained for EGFR localization, the intensity of EGFR staining in the cell membrane decreased in doxorubicintreated cells compared with control cells (Fig. 3b). These data suggest that doxorubicin treatment reduces EGFR levels and phosphorylation and thus decreases EGFR activity.

To further investigate the importance of EGFR activity for HMG-CR expression, cells were treated with the EGFR inhibitor AG1478. AG1478 treatment decreased levels of both total EGFR and phospho-EGFR and also downregulated $\mathrm{HMG}-\mathrm{CR}$ (Fig. 3c). Co-treatment of cells with doxorubicin and AG1478 dramatically decreased HMG-CR concomitantly with decreased levels of EGFR, phosphoEGFR, and phospho-Src (Fig. 3c and Suppl. Figure 1B). Next, we tested whether EGFR activation attenuates doxorubicin-induced signaling pathways and cell death. Epidermal growth factor (EGF) treatment resulted in Src activation and a slight increase in HMG-CR levels (Fig. 3d). Treatment of cells with EGF and doxorubicin together resulted in attenuation of the doxorubicin-induced EGFR and Src inactivation, HMG-CR downregulation, and caspase 3 activation as determined by PARP cleavage (Fig. 3d and Suppl. Figure 1C). Interestingly, EGFR levels were more severely decreased in co-treated cells than in cells 
A

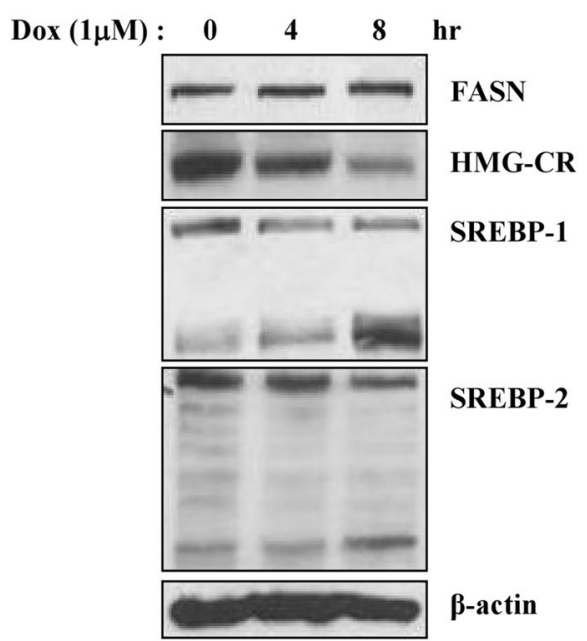

B
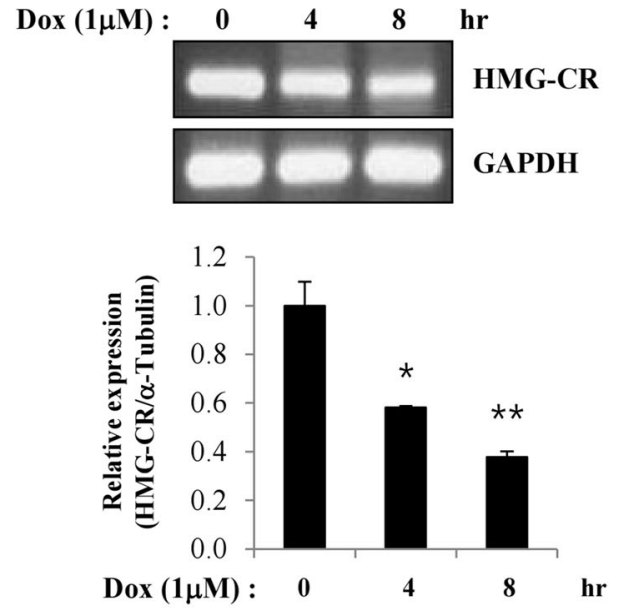

C

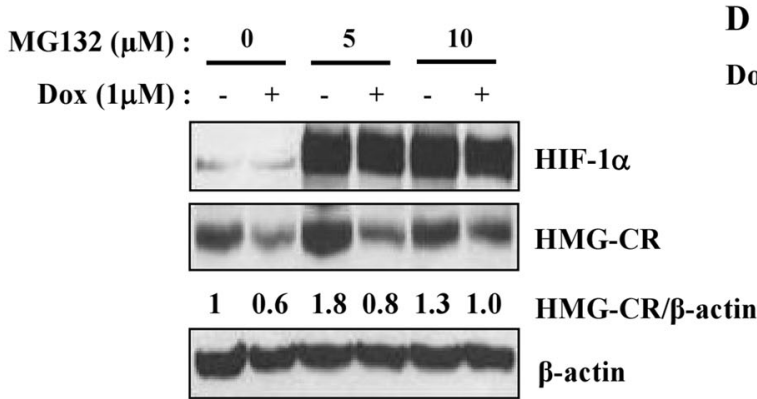

D
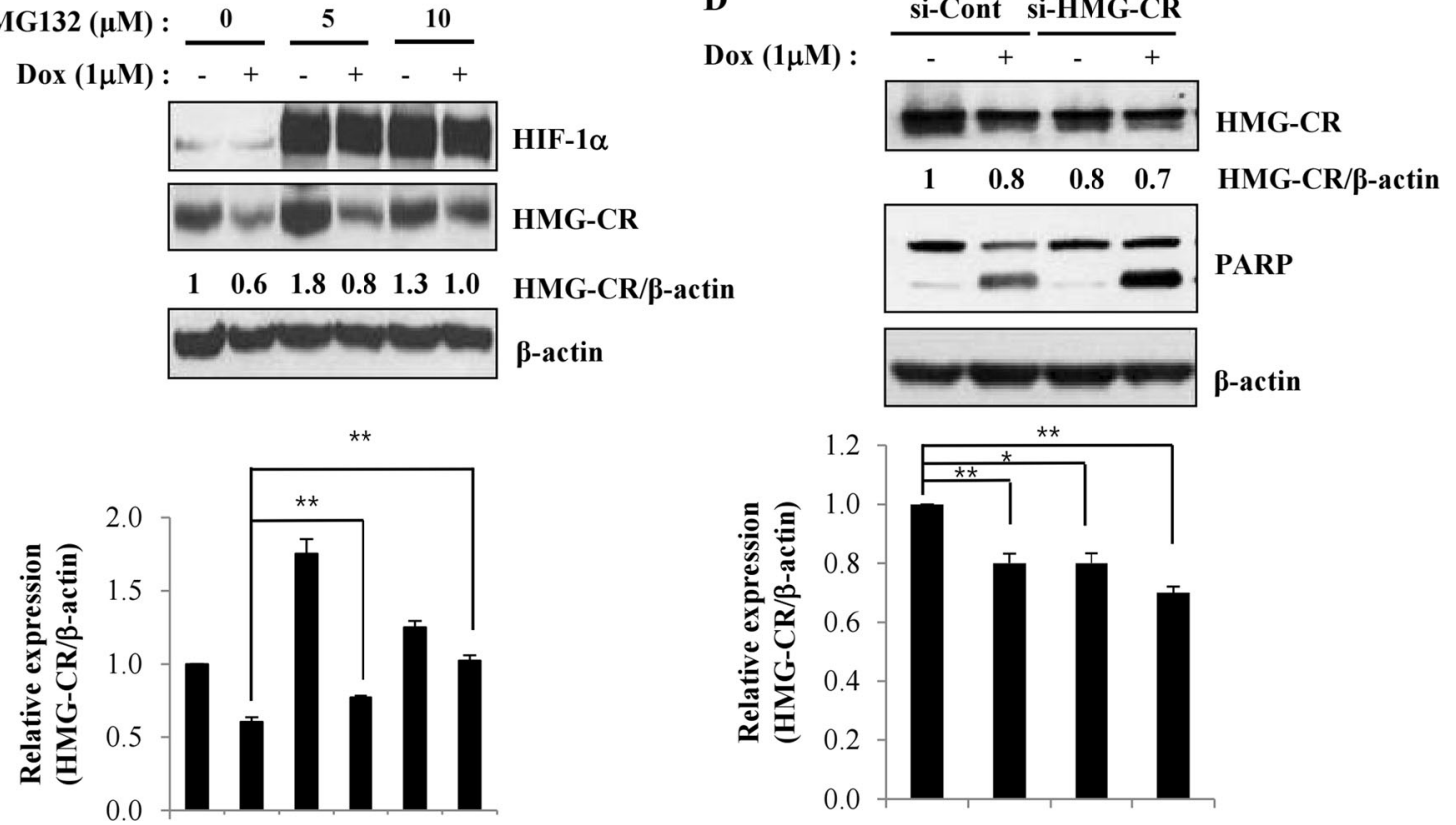

Fig. 2 Effects of doxorubicin on HMG-CR expression. a Serumstarved A431 cells were treated with $1 \mu \mathrm{M}$ doxorubicin and then subjected to immunoblot analysis using the indicated antibodies. $\beta$ actin was used as a loading control. b Serum-starved A431 cells were treated with $1 \mu \mathrm{M}$ doxorubicin for 0,4 , or $8 \mathrm{~h}$ and total RNA was extracted and subjected to reverse transcription (RT)-PCR to assess HMG-CR mRNA levels. GAPDH was used as loading control. Total RNA was also subjected to quantitative RT-PCR and normalized with $\alpha$-Tubulin (vs. 0 h, $* p<0.05, * * p<0.01$ ). c Serum-starved A431 cells were pretreated with 5 or $10 \mu \mathrm{M}$ MG132 for $30 \mathrm{~min}$ followed by treatment with $1 \mu \mathrm{M}$ doxorubicin for $8 \mathrm{~h}$. Cell lysates were processed

treated with doxorubicin alone, likely due to additional receptor internalization and downregulation by EGF (Fig. 3d). These data suggest that inactivation of EGFR and Src, and thus HMG-CR downregulation, is one mechanism for doxorubicin-induced cell death.

for immunoblot analysis using anti-HMG-CR and anti- $\beta$-actin antibodies. The levels of HMG-CR were quantified by a densitometry and normalized to $\beta$-actin levels. The ratio of $\mathrm{HMG}-\mathrm{CR} / \beta$-actin was set at 1 in the control cells. d A431 cells were knockdowned by siRNA, serum-starved, and treated with $1 \mu \mathrm{M}$ doxorubicin. Cell lysates were subjected to immunoblot analysis using the indicated antibodies. The experiments were performed three times with similar results. The levels of HMG-CR were quantified by a densitometry and normalized to $\beta$-actin levels. The ratio of HMG-CR/ $\beta$-actin was set at 1 in the control cells. Error bars represent the standard deviation of the mean of three measurements $\left({ }^{*} p<0.05, * * p<0.01\right)$

\section{Src activity regulates HMG-CR levels in cancer cells}

Because, Src is one of the major downstream targets of EGFR signaling and Src activation was dramatically decreased by doxorubicin, we investigated whether Src regulates HMG-CR 
A

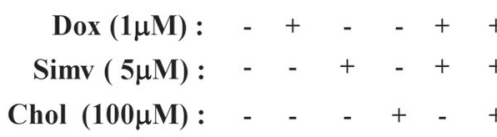

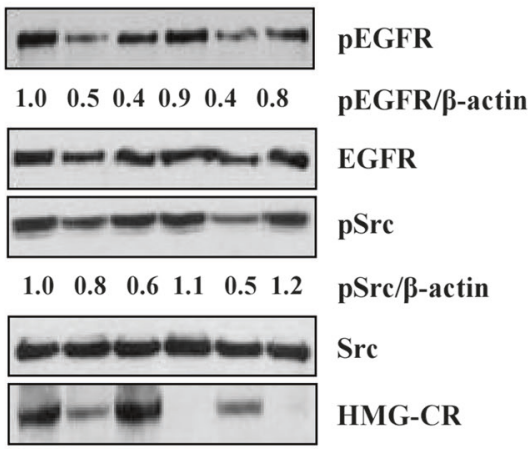

$\begin{array}{lllllll}1.0 & 0.7 & 1.5 & 0.0 & 0.9 & 0.1 & \text { HMG-CR/ } \beta \text {-actin }\end{array}$
B
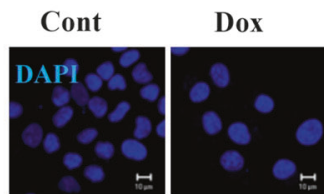

Cont
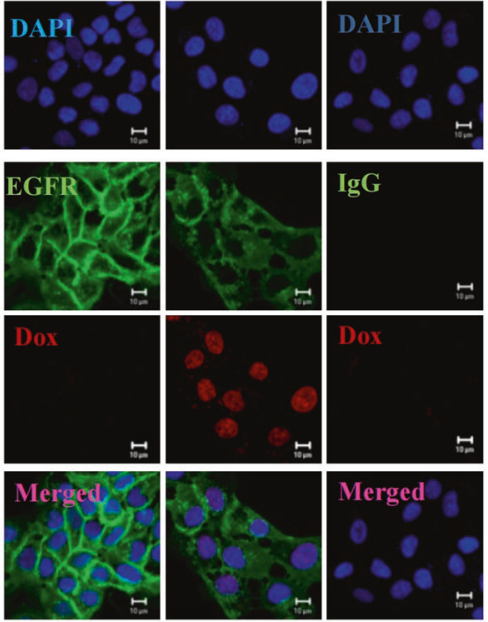

IgG
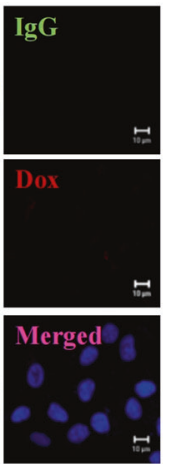

$\beta$-actin

C

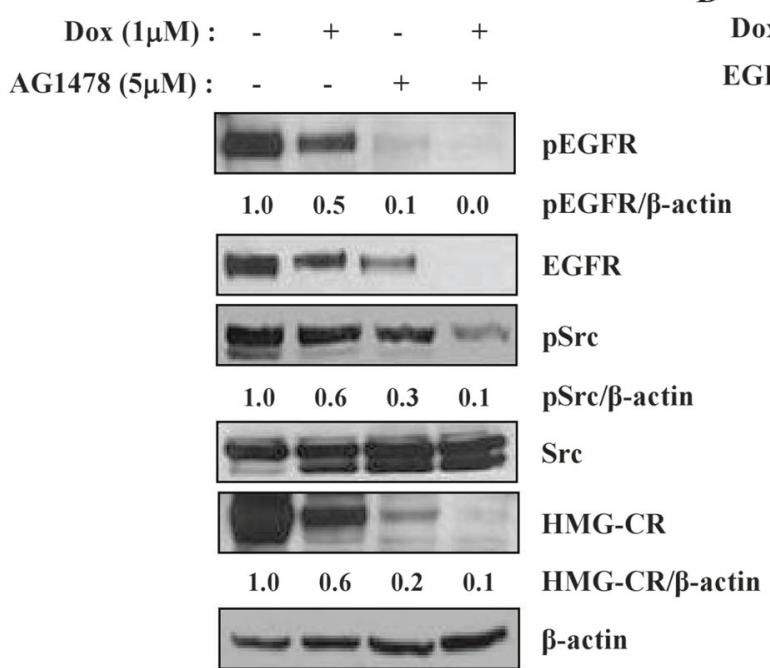

D Dox $(1 \mu \mathrm{M}):-\quad+\quad-\quad+$ GF $(\operatorname{lnM}):-\quad-\quad+\quad+$

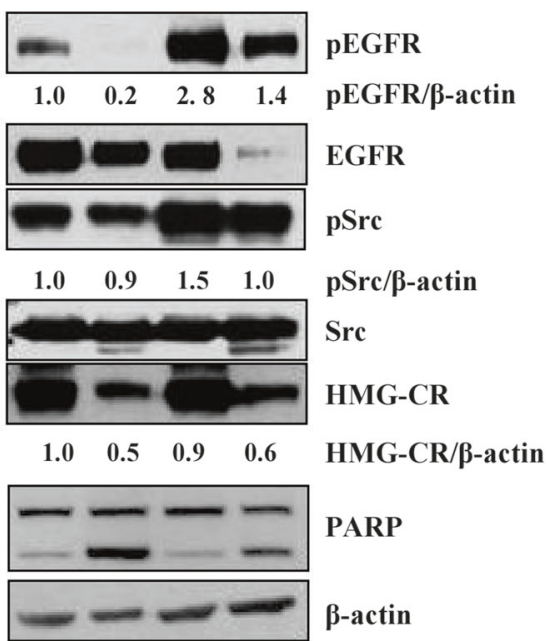

A431 cells were treated either with $1 \mu \mathrm{M}$ doxorubicin, $5 \mu \mathrm{M}$ AG1478, or $1 \mu \mathrm{M}$ doxorubicin and $5 \mu \mathrm{M}$ AG1478 together for $8 \mathrm{~h}$. Cell lysates were subjected to immunoblot analysis using the indicated antibodies. d Serum-starved A431 cells were treated with either $1 \mu \mathrm{M}$ doxorubicin, $1 \mathrm{nM}$ EGF, or $1 \mu \mathrm{M}$ doxorubicin and $1 \mathrm{nM}$ EGF together for 8 $\mathrm{h}$, and the cell lysates were subjected to immunoblot analysis using the indicated antibodies. The levels of proteins were quantified by densitometry and normalized with $\beta$-actin. These experiments were performed three times with comparable results

to A431 cells, we employed other cancer cell lines. Doxorubicin treatment decreased activation of EGFR and Src, induced HMG-CR downregulation, and increased PARP cleavage in prostate cancer cell lines DU145 and PC3 (Fig. 4c and Suppl. Figure 2C). Overexpression of active-Src in PC3 cells increased HMG-CR levels, and thus attenuated doxorubicin-induced HMG-CR downregulation and PARP cleavage (Fig. 4d and Suppl. Figure 2D). OVCAR8 is an 
A

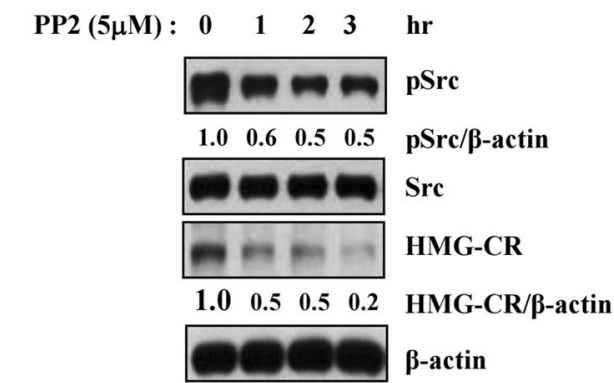

C

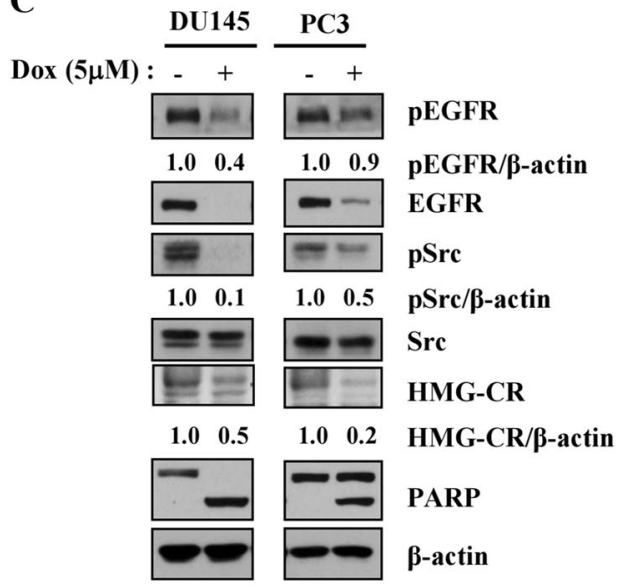

$\mathbf{E}$

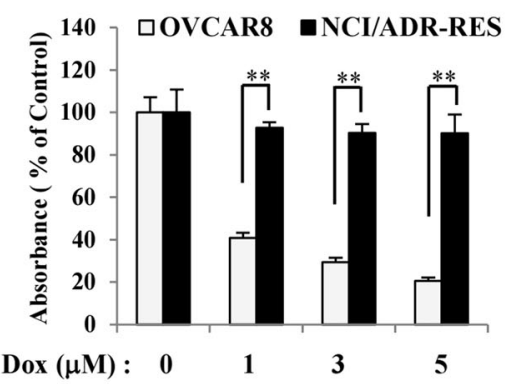

Fig. 4 Association of Src activity with HMG-CR levels in various cancer cell lines. a Serum-starved A431 cells were treated with $5 \mu \mathrm{M}$ PP2 for the indicated times, and then the cell lysates were subjected to immunoblot analysis using the indicated antibodies. b A431 cells were transfected with either mock vector or active-Src vector for $24 \mathrm{~h}$ and then treated with $1 \mu \mathrm{M}$ doxorubicin for $24 \mathrm{~h}$. Cell lysates were subjected to immunoblot analysis using the indicated antibodies. c Serumstarved PC3 and DU145 cells were treated with $5 \mu \mathrm{M}$ doxorubicin for $24 \mathrm{~h}$, and the cell lysates were subjected to immunoblot analysis using the indicated antibodies. $\mathbf{d}$ PC 3 cells were transfected with either mock vector or HA-tagged active-Src vector for $24 \mathrm{~h}$ and then treated with

ovarian cancer cell line, and NCI/ADR-RES is an anti-cancer drug-resistant cell line derived from OVCAR8 [21]. Doxorubicin-induced cell death in OVCAR8 cells, but not in related anti-cancer drug-resistant NCI/ADR-RES cells (Fig. 4e). Doxorubicin treatment resulted in dramatic Src

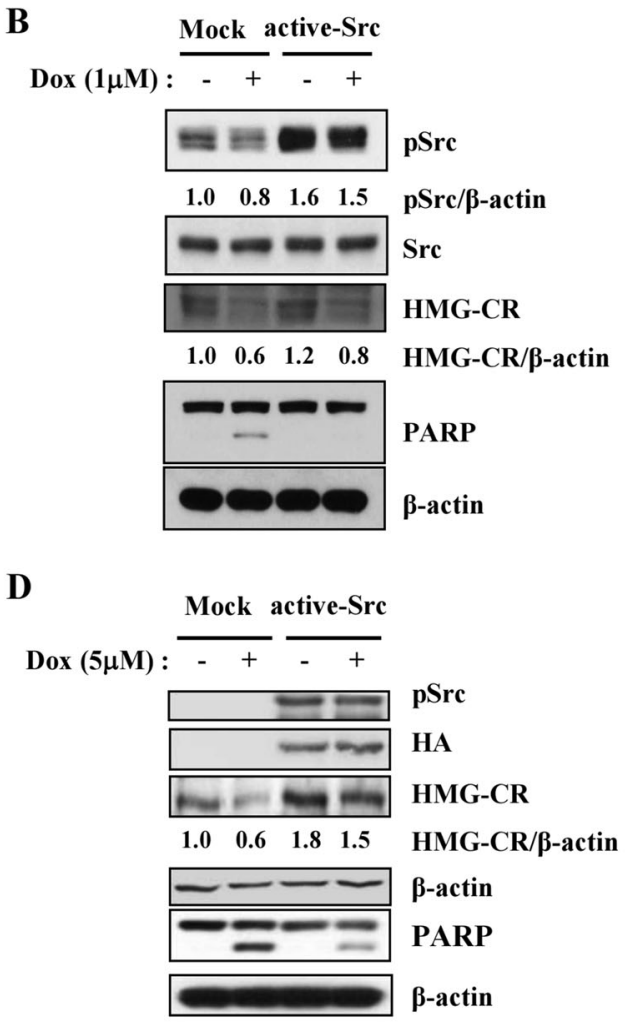

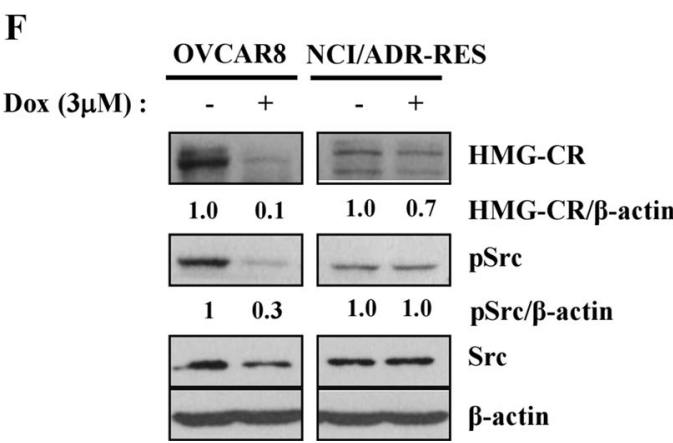

$1 \mu \mathrm{M}$ doxorubicin. Cell lysates were subjected to immunoblot analysis using the indicated antibodies. e Serum-starved OVCAR8 and NCI/ ADR-RES cells were treated with the indicated concentrations of doxorubicin for $48 \mathrm{~h}$. Cell growth inhibition was measured by the MTS assay. Error bars represent the standard deviation of the mean of three measurements $(* * p<0.01)$. f Serum-starved OVCAR8 and NCI/ ADR-RES cells were treated with $3 \mu \mathrm{M}$ doxorubicin for $48 \mathrm{~h}$, and the cell lysates were subjected to immunoblot analysis using the indicated antibodies. The levels of proteins were quantified by densitometry and normalized with $\beta$-actin. Similar results were observed in threeindependent experiments

inactivation and HMG-CR downregulation in OVCAR8 cells, but these effects were minimal in NCI/ADR-RES cells (Fig. 4f and Suppl. Figure 2E). Together, these data indicate that EGFR-Src inactivation is critical for HMG-CR downregulation induced by doxorubicin. 


\section{Cholesterol attenuates the anti-cancer effect of doxorubicin}

HMG-CR converts HMG-CoA to mevalonate, a key step in cholesterol biosynthesis [29]. Because doxorubicin downregulated HMG-CR (Fig. 2) and decreased cholesterol levels (Fig. 1), we determined whether the addition of exogenous mevalonate can restore cholesterol levels and reverse doxorubicin-induced cell death. Although cholesterol addition reversed doxorubicin-induced cell morphology changes, mevalonate had little effect (Fig. 5a). Cholesterol addition rescued cells from doxorubicininduced apoptosis, whereas cholesterol depletion accelerated this apoptosis. Mevalonate addition, however, only somewhat attenuated doxorubicin-induced apoptosis (Fig. 5b). Cholesterol addition increased cellular cholesterol levels within $2 \mathrm{~h}$; however, mevalonate minimally affected cholesterol levels even after $8 \mathrm{~h}$ (Fig. 5c). Consistent with these results, cholesterol addition restored activation of both EGFR and Src in the doxorubicin-treated cells, whereas mevalonate addition had little effect (Fig. 5d). These data indicate that cholesterol levels are critical for doxorubicininduced cell death. To further investigate whether cholesterol levels are associated with the anti-cancer effects of doxorubicin in vivo, mice were fed either a normal diet (Chow) or a high-cholesterol diet (Chol) for 3 days before xenografting with A431 cells. Blood cholesterol levels were increased in the high-cholesterol-diet group compared with in the normal-diet group (Fig. 6a). Tumor growth appeared to be faster in the high-cholesterol-diet group than in the normal-diet group. In addition, tumor growth was slowed by doxorubicin treatment in the normal-diet group, but this inhibition was attenuated in the high-cholesterol-diet group (Fig. 6b). The mice fed a normal diet and treated with doxorubicin, which had the smallest tumor volumes, also had the lowest EGFR levels and highest cleaved (active) caspase 3 levels than any other group (Fig. 6c). These data indicate that cholesterol levels are critical for the anti-cancer efficacy of doxorubicin.

To further investigate the effect of cholesterol on doxorubicin efficacy in an entire organism in vivo, we also employed $C$. elegans. Because, C. elegans cannot synthesize cholesterol independently [30], it provides a convenient model to test the effects of cholesterol deprivation without the use of additional tools, such as cholesterol inhibitors. Previously, we generated the C. elegans jgIs 25 strain, which expresses chimeric LET-23/EGFR with two mutations (T790M and L858R) in the human EGFR kinase domain [23]. As shown in our previous report [23] and in the present study, these mutations induce a high incidence of the multivulva phenotype, which is an indicator of hyperplasia, compared to wild type (Fig. 6d, left and center panels). Treatment of jgIs 25 worms with doxorubicin inhibited multivulva formation (Fig. 6d, right panel), and the degree of inhibition was greater in the absence than in the presence of cholesterol (Fig. 6e, f). These data further confirm that regulation of cholesterol levels is important for doxorubicin efficacy.

\section{Discussion}

Most anti-cancer agents are DNA-damaging agents, including doxorubicin. Although doxorubicin is commonly used because it is an effective chemotherapeutic drug with a broad spectrum, its side effect is a dose-dependent cardiotoxicity, which leads to cardiopathy and heart failure [1]. This side effect could be overcome by increasing doxorubicin efficacy, and thus decreasing the dose of doxorubicin needed. Anthracyclines like doxorubicin target topoisomerase II, leading to DNA damage, and induce cell death via multiple mechanisms. Most anthracyclines are known to increase reactive oxygen species, which leads to oxidative stress [31]. In this study, we identified an EGFR/Src/HMG$\mathrm{CR}$ pathway that is involved in a new mechanism of doxorubicin-induced cell death, suggesting that cholesterol control is critical to doxorubicin efficacy.

Cholesterol is crucial for maintaining cellular homeostasis. It is a precursor for steroid hormones and a component of membrane bilayers that is essential for their integrity and to enable cell proliferation [32]. Some cholesterol is provided by the diet, but it is primarily synthesized in the liver and distributed to cells via the blood stream. Cancer cells also synthesize cholesterol through activation of oncogenic processes [33]. For example, in breast cancer cells, EGF is known to increase expression and activation of HMG-CR, which is a critical rate-limiting enzyme in cholesterol biosynthesis, via the EGFR2 (ErbB2) pathway [34]. Intriguingly, our study found that doxorubicin treatment decreased EGFR levels and downregulated HMG-CR, and thus decreased cholesterol levels (Figs. 1d and 3a). Knockdown of HMG-CR enhanced PARP cleavage, which is an indicator of caspase-3 activation (Fig. 2d), suggesting that HMG-CR downregulation is important for doxorubicin-induced cell death. Lowering cholesterol levels using either $\mathrm{M} \beta C \mathrm{C}$, a cholesterol depleting agent, or simvastatin, an HMG-CR inhibitor, enhanced doxorubicininduced cell death (Fig. 1). However, addition of exogenous cholesterol alleviated doxorubicin-induced cell death (Fig. 1), indicating that cholesterol levels are critical for doxorubicin sensitivity.

How cholesterol can regulate doxorubicin sensitivity? Cholesterol is a critical component of specialized membrane microdomains known as lipid rafts, which play a key role in the cellular signaling network [12]. Cholesterol accumulation in cancer has been reported and increased cholesterol 
A

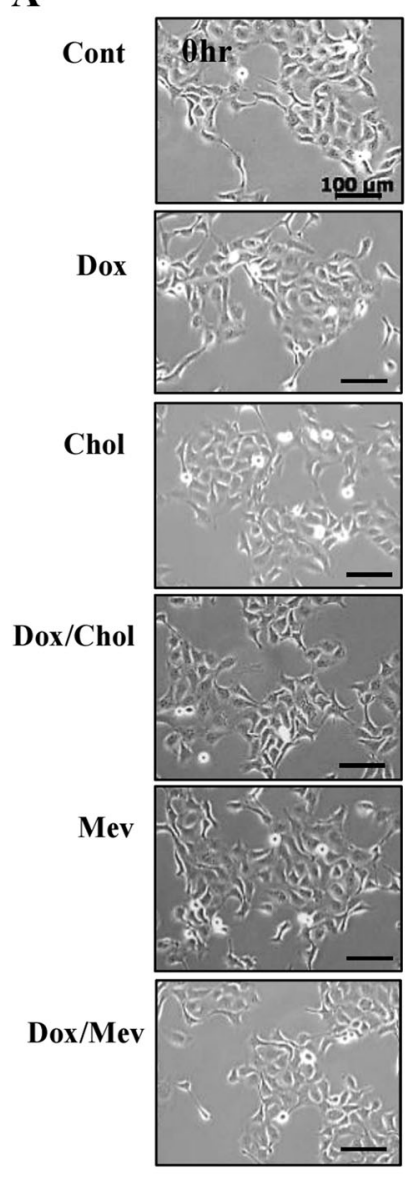

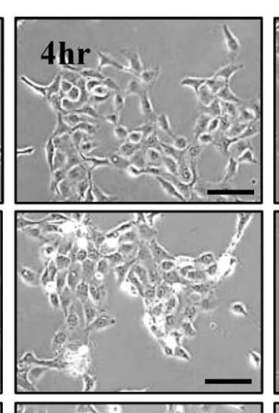
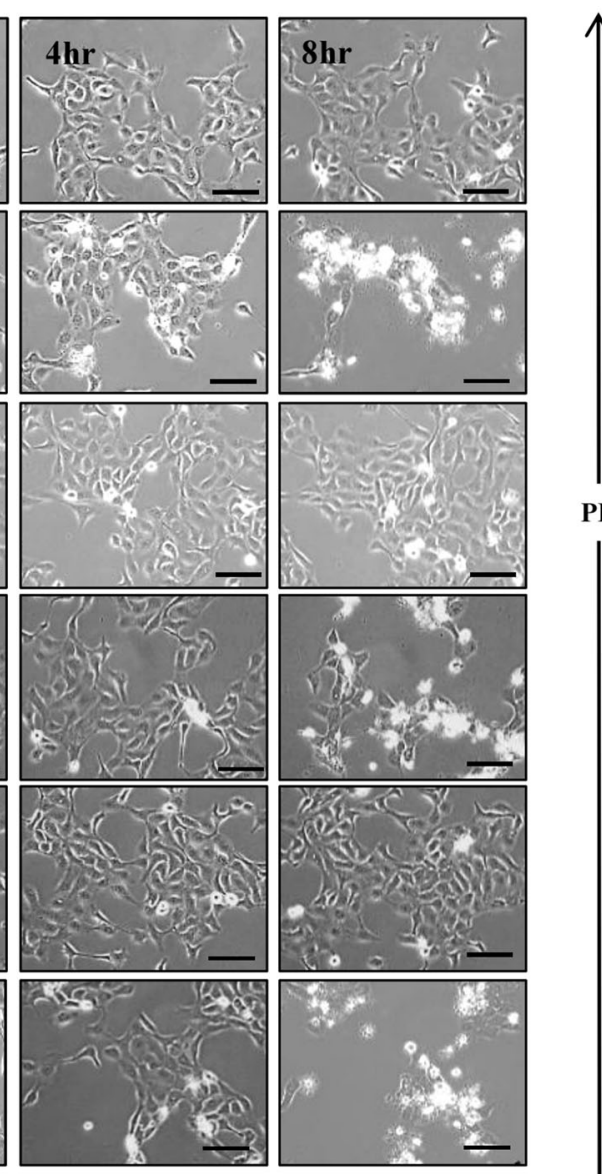

B
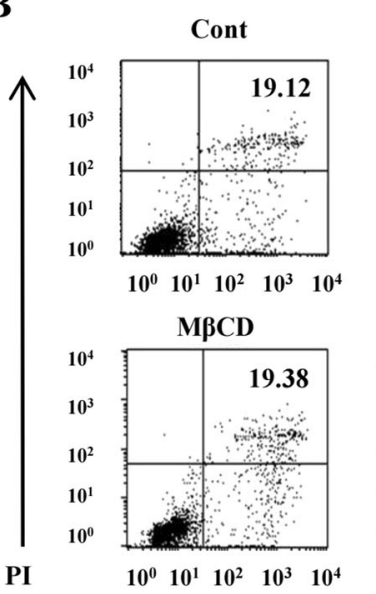

PI

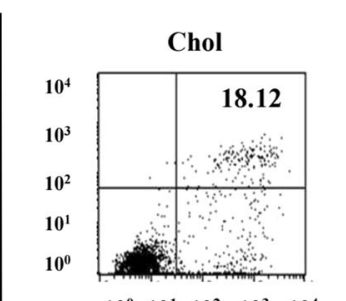

$\begin{array}{lllll}10^{0} & 10^{1} & 10^{2} & 10^{3} & 10^{4}\end{array}$
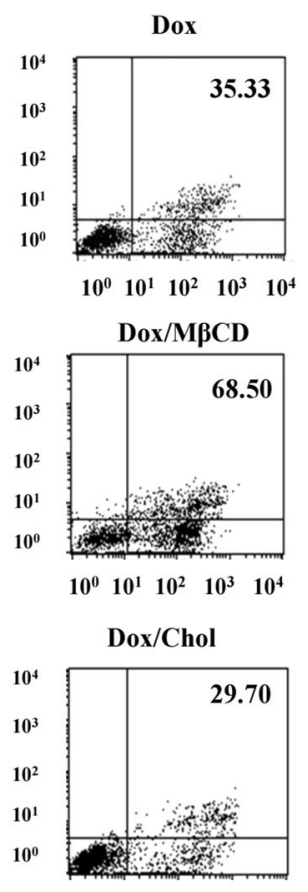

$\begin{array}{lllll}10^{0} & 10^{1} & 10^{2} & 10^{3} & 10^{4}\end{array}$
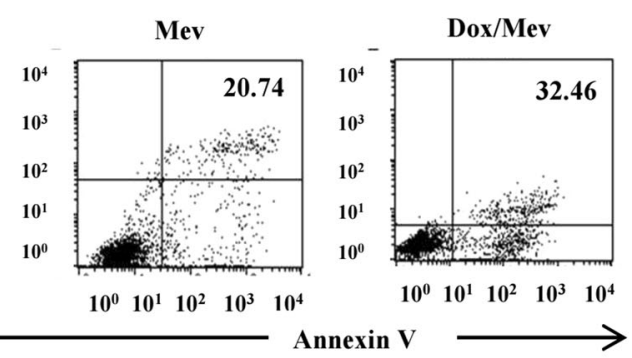

Annexin V
C

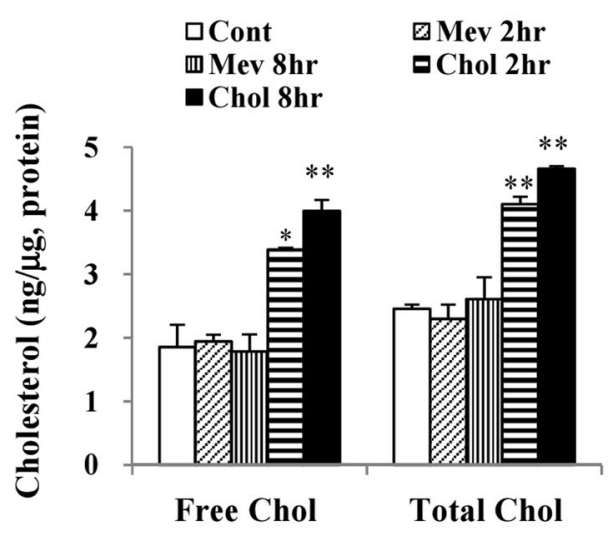

D

$\begin{array}{rrrrrrr}\operatorname{Mev}(300 \mu M): & - & - & - & - & + & + \\ \text { Chol }(100 \mu M): & - & - & + & + & - & - \\ \operatorname{Dox}(1 \mu M): & - & + & - & + & - & +\end{array}$

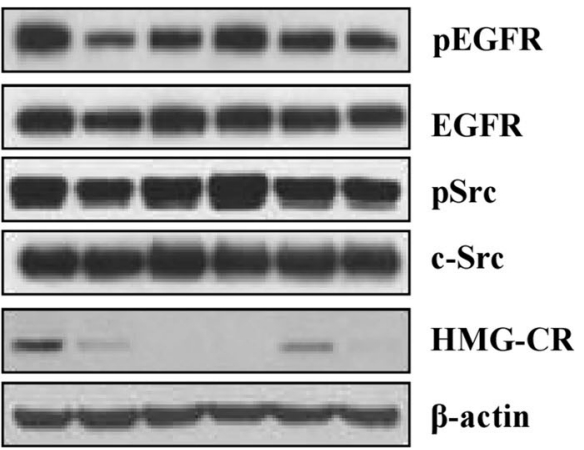

levels have been associated with elevated levels of lipid rafts on the cell surface [13, 35]. In addition, cholesterol depletion from the cell membrane results in lipid raft internalization from the cell membrane, causing a deregulation of cellular signaling that leads to cell death [13].
Given these findings, it is likely that the decrease in cholesterol caused by doxorubicin resulted in decreased levels of lipid rafts on the cell surface. As expected, doxorubicin reduced the levels of lipid rafts on the cell surface as determined by GM-1 staining, which is a marker for lipid 
Fig. 5 Effects of mevalonate on doxorubicin-induced cell death. a Serum-starved A431 cells were treated with either $1 \mu \mathrm{M}$ doxorubicin, $100 \mu \mathrm{M}$ cholesterol, $300 \mu \mathrm{M}$ mevalonate, $1 \mu \mathrm{M}$ doxorubicin and 100 $\mu \mathrm{M}$ cholesterol, or $1 \mu \mathrm{M}$ doxorubicin and $300 \mu \mathrm{M}$ mevalonate for $8 \mathrm{~h}$. Images were taken using Zeiss Axio observer live cell station. Magnification: $\times 100$, Scale bars $=100 \mu$ M. b Serum-starved A431 cells were treated with $1 \mu \mathrm{M}$ doxorubicin, $500 \mu \mathrm{M} \mathrm{M} \beta C D, 300 \mu \mathrm{M}$ mevalonate, $100 \mu \mathrm{M}$ cholesterol, $500 \mu \mathrm{M} \mathrm{M} \beta \mathrm{CD}$ and $1 \mu \mathrm{M}$ doxorubicin, $100 \mu \mathrm{M}$ cholesterol and $1 \mu \mathrm{M}$ doxorubicin, or $300 \mu \mathrm{M}$ mevalonate and $1 \mu \mathrm{M}$ doxorubicin for $8 \mathrm{~h}$, stained with annexin V-FITC and PI, and analyzed by flow cytometry. Cells that were positive stained by annexin V-FITC (early and late apoptosis) were quantitated, and the subpopulations were considered as overall apoptotic cells. c Serumstarved A431 cells were treated with either $300 \mu \mathrm{M}$ mevalonate or 100 $\mu \mathrm{M}$ cholesterol. Free cholesterol and total cholesterol were measured using the Amplex Red cholesterol assay kit as described in the "Materials and Methods". Error bars represent the standard deviation of the mean of three measurements (vs. control, $* p<0.05$, ** $p<0.01$ ). d Serum-starved A431 cells were treated as in the $\mathbf{b}$, and the cell lysates were subjected to immunoblot analysis using the indicated antibodies. The experiments were performed three times with comparable results

rafts (Fig. 1e, f). The decrease in cell surface lipid rafts is probably mediated via their internalization or decreased trafficking to the cell surface, because GM-1 was stained inside of the cell (Fig. 1e, f). Because lipid rafts are known to be enriched in signaling molecules including EGFR [36], the decrease in surface lipid rafts might reduce cell survival by affecting signaling in the doxorubicin-treated cells. Cholesterol addition appeared not to inhibit doxorubicin internalization because comparable levels of doxorubicin were observed in the cells treated with both doxorubicin and cholesterol as in the cells treated with only doxorubicin (Fig. 1e).

Although mitochondria are cholesterol-low organelles, several lines of studies have reported that cholesterol levels of mitochondria isolated from hepatic cancer cells are elevated and that this phenomenon is correlated with resistance to apoptotic cell death [37-39]. In addition, compared with chow diet-fed mice, hepatocytes from high-cholesterol-dietfed mice increase levels of not only pro-apoptotic Bax protein but also anti-apoptotic proteins, Mcl-1 and Bcl-xL as a compensatory anti-apoptosis response [39]. We observed that doxorubicin decreased cholesterol levels in mitochondria (Suppl. Figure 3). Therefore, it is also possible that decreasing cholesterol levels by HMG-CR downregulation results in a deficit of mitochondrial cholesterol, facilitating mitochondrial apoptosis pathway through mitochondrial membrane permeabilization and release of apoptotic proteins.

Mevalonate, a precursor for cholesterol synthesis, is formed from HMG-CoA by HMG-CR [7]. Mevalonate addition recovered cholesterol levels in simvastatin-treated cells (Suppl. Figure 4A). However, mevalonate did not fully recover cholesterol levels in doxorubicin-treated cells, and therefore only minimally attenuated the cytotoxic effects of doxorubicin (Fig. 5 and Suppl. Figure 4B). Because farnesyl pyrophosphate is a key intermediate in the biosynthesis of isoprenoids and cholesterol after mevalonate synthesis [39], we tested whether doxorubicin treatment affects expression of farnesyl pyrophosphate synthase (FPPS) and geranylgeranyl pyrophosphate synthase (GGPPS). Doxorubicin treatment had little effect on GGPPS expression but decreased FPPS expression significantly regardless of mevalonate addition, although mevalonate addition alone appeared to increase FPPS expression (Suppl. Figure 5A). Therefore, it is likely that the lack of increase in cholesterol levels by mevalonate is due to the decrease in FPPS rather than an increased synthesis of isoprenoids. FPP can be converted into squalene by squalene synthase, which catalyzes the first step in the committed pathway for cholesterol synthesis [39]. Squalene administration partially restored total cholesterol levels, whereas it did not affect the levels of free cholesterol (Suppl. Figure 5B). Consequently, squalene administration did not attenuate doxorubicin-induced cell death (Suppl. Figure 5C). Similar to our observation, squalene did not protect NBL cells from doxorubicininduced toxicity [40]. It is possible that doxorubicin treatment inhibits the enzymatic conversion of intermediates such as mevalonate or squalene to cholesterol, leading to cellular cholesterol depletion. Although doxorubicin increased the cleavage of SREBP-2, a well-known regulator of HMG-CR, levels of HMG-CR mRNA were reduced (Fig. 2b). It is likely that factors other than SREBP-2 activation may influence the regulation of HMG-CR expression upon doxorubicin treatment.

EGFR family members are linked to cholesterol metabolism. EGF and neuregulin increase expression and activation of HMG-CR via the ErbB2 (EGFR2) and ErbB4 (EGFR4) pathways, respectively [34, 41], leading to an increase in cholesterol biosynthesis. Neuregulin-activated ErbB4 induces activation of SREBP-2, a transcription factor for HMG-CR, and thus HMG-CR upregulation [41]. Given that the EGFR/Src pathway is a well-known oncogenic pathway [42], it is intriguing that doxorubicin treatment induces EGFR downregulation, resulting in EGFR and Src inactivation (Figs. 3 and 4), which was important for HMGCR downregulation. EGFR inhibition enhances the cytotoxic effects of doxorubicin in rat hepatoma cells [43] and EGFR overexpression is associated with decreased survival in breast cancer patients treated with doxorubicin [44], indicating an association between EGFR and doxorubicin sensitivity. EGFR inhibitor AG1478 dramatically downregulated $\mathrm{HMG-CR}$ levels, and further downregulation was observed when combined with doxorubicin (Fig. 3c). EGF attenuated HMG-CR downregulation, and thus decreased cell death pathway activity as determined by PARP cleavage in the doxorubicin-treated cells (Fig. 3d). In addition, active-Src expression upregulated HMG-CR levels and 

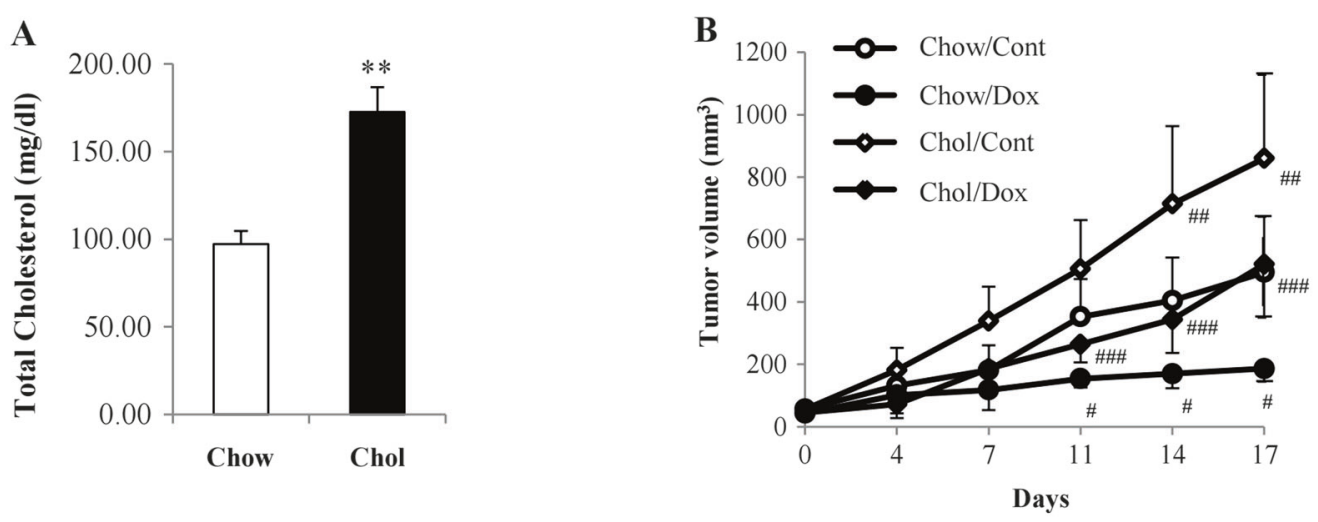

C

Chow/Cont

Chow/Cont

Chow/Dox

Chol/Cont

Chol/Dox
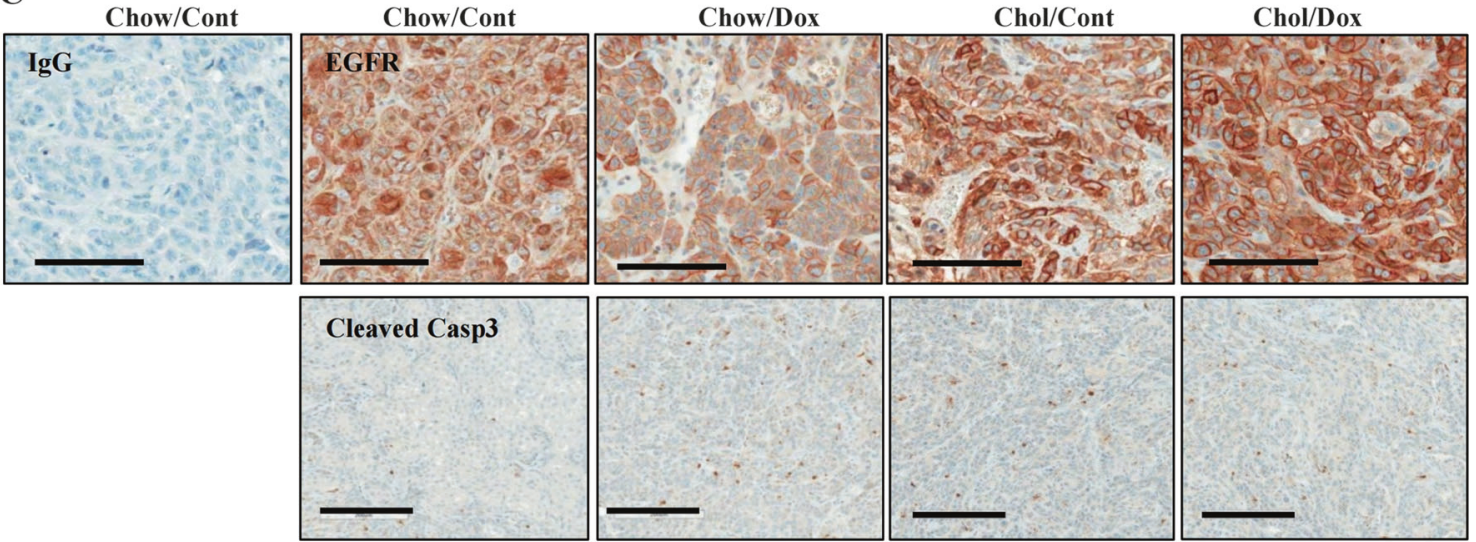

Cleaved Casp3
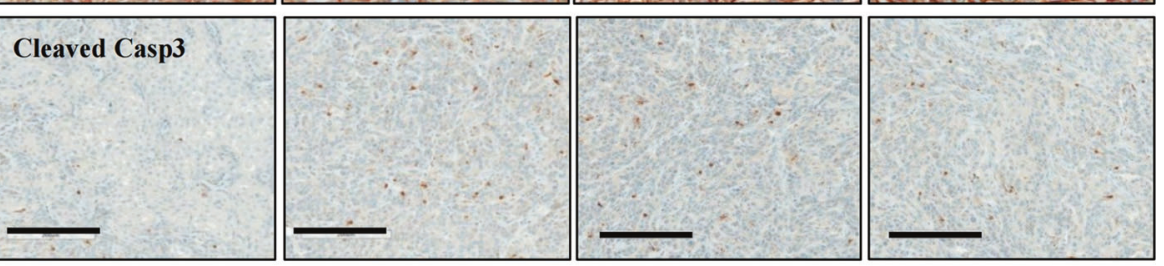

D

Wild type

jgIs 25

jgIs 25 (Chol- /Dox +$)$
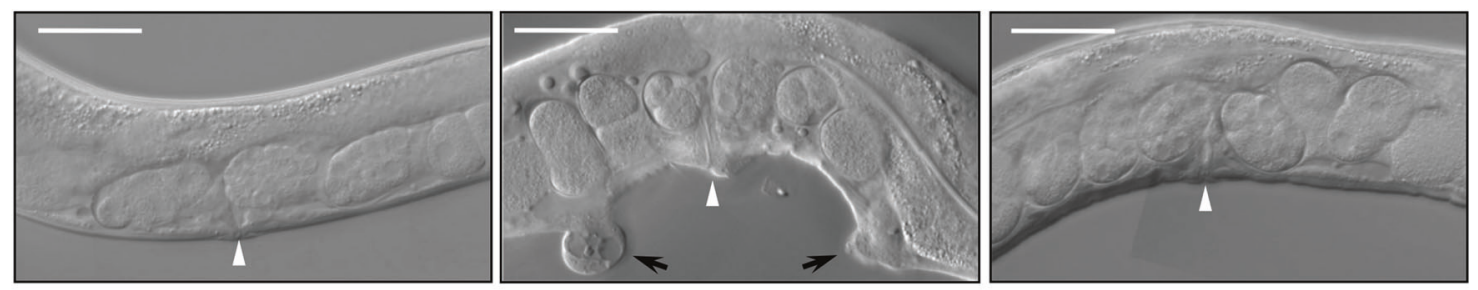

E
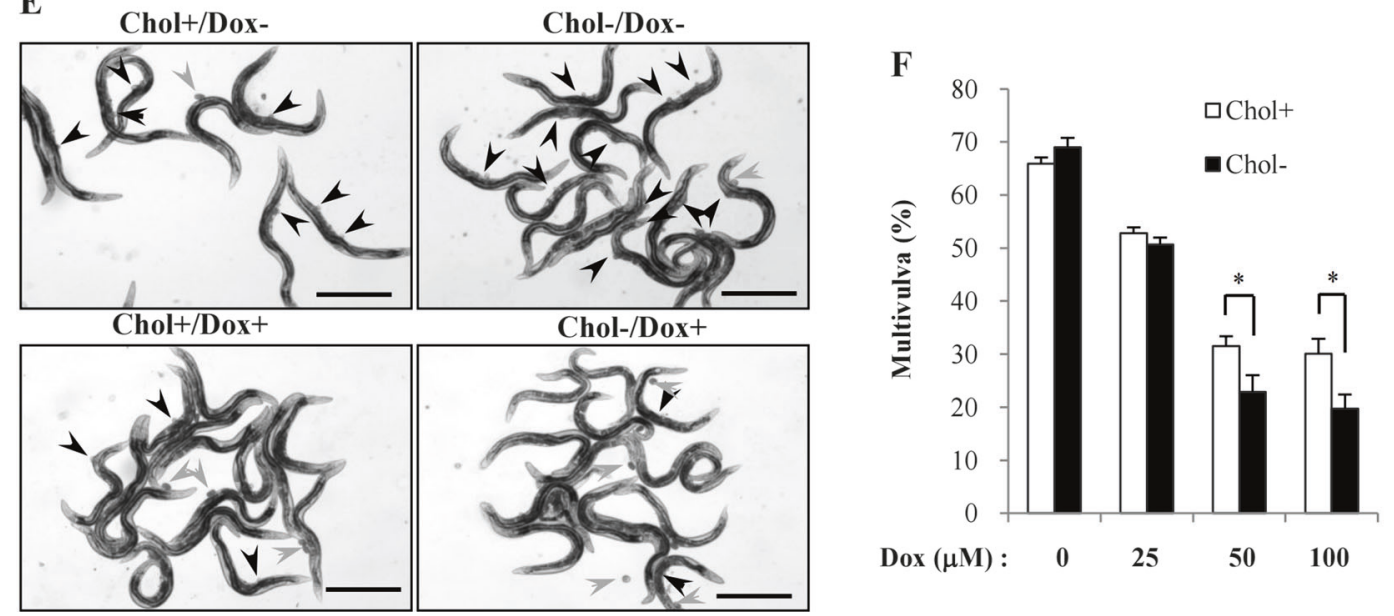
Fig. 6 Effects of cholesterol diet on anti-cancer effects of doxorubicin in vivo. a Chow and high-cholesterol diet were started 3 days before injection of A431 cells into mice. Blood was drawn from the mice and the serum was isolated, and serum cholesterol levels were determined by Amplex Red cholesterol assay kit as described in the "Materials and Methods". Error bars represent the standard deviation of the mean of three measurements (vs. Chow, $* * p<0.01$ ). b Mice were treated as described in the "Materials and Methods". An intraperitoneal injection of doxorubicin $(0.5 \mathrm{mg} / \mathrm{kg})$ was given twice a week into the tumorbearing mice. $(p<0.05$, \#Chow/Dox vs. Chow/Cont, \#\#Chol/Cont vs. Chow/Cont, \#\#\#Chol/Dox vs. Chow/Dox). c Mice were treated as in b, killed, and their tumor tissues were stained with anti-EGFR antibody and anti-cleaved caspase 3 antibody. Representative immunohistochemistry images were analyzed by microscopy. Magnification: $\times 200$, Scale bars $=100 \mu \mathrm{M}$. d Images of wild-type C. elegans (left panel) and the mutant jgIs 25 strain with multivulva (center panel) were taken using nomarski optics. The right panel shows decreased multivulva formation in the jgIs 25 strain that was treated with $50 \mu \mathrm{M}$ doxorubicin in cholesterol-depleted media. White arrowheads indicate vulvae and black arrows indicate the hyperplasic region of a multivulva animal. Magnification: $\times 630$, Scale bars $=50 \mu \mathrm{M}$. e and $\mathbf{f} j g I s 25$ strains were treated either without or with doxorubicin $(50 \mu \mathrm{M}$ in $\mathbf{e}$ and $0-100 \mu \mathrm{M}$ in f) in the absence or presence of $20 \mu \mathrm{g} / \mathrm{ml}$ cholesterol in the media for 3 days, followed by a two day recovery in the normal growth medium as described in the "Materials and Methods". Images of multivulva formation were taken e and the number of hyperplasiabearing animals was counted with a dissecting microscope f. Black arrows indicate the hyperplasic region of multivulva animals and gray arrows indicate eggs. Magnification: $\times 50$, Scale bars $=500 \mu \mathrm{M}$. Error bars represent the standard deviation of the mean of three measurement. $(* p<0.05)$. The experiments were performed two times with similar results

attenuated doxorubicin-induced PARP cleavage (Fig. 4b, d). This EGFR/Src/HMG-CR pathway is not limited to A431 cells, because we observed similar phenomena in cell lines from several different types of cancers, including prostate cancer, ovarian cancer, and breast cancer (Fig. 4 and Suppl. Figure 6A). Doxorubicin-sensitive OVCAR cells showed doxorubicin-dependent HMG-CR downregulation, whereas resistant NCI/ADR-RES cells showed little change in HMG-CR levels after doxorubicin treatment. Doxorubicin treatment also reduced EGFR activation and the levels of HMG-CR in the human lung cancer cell line H1975, which expresses a constitutively active EGFR with T790M and L858R mutations (Suppl. Figure 6B). Interestingly, other DNA-damaging agents, including CDDP, bleomycin, and etoposide, induced downregulation of EGFR, pEGFR, pSrc, and HMG-CR, and thus increased PARP cleavage (Suppl. Figure 7A-C). These data suggest that downregulation of the EGFR/Src/HMG-CR pathway plays a role in the cell death that is induced by DNAdamaging agents such as doxorubicin. In addition, as shown in Suppl. Figure 8, doxorubicin treatment decreased the levels of pEGFR, pSrc, and HMG-CR within as little as $1 \mathrm{~h}$ as an early event. However, free cholesterol levels were not significantly decreased until $8 \mathrm{~h}$ of doxorubicin treatment (Fig. 1d). These results indicate that EGFR/Src/HMG-CR pathway downregulation occurs earlier than reduction of cholesterol, and therefore this pathway is not secondary to cholesterol decrease by doxorubicin.

The use of statins, which are inhibitors of HMG-CR, to reduce cholesterol synthesis is known to potentiate the antitumor activity of doxorubicin in an in vivo murine model [37]. In our study, we tested whether a high-cholesterol diet decreases doxorubicin efficacy in an in vivo murine model. In the high-cholesterol-diet group, tumors grew faster and growth inhibition by doxorubicin was smaller than in the normal-diet group (Fig. 6b). Doxorubicin treatment decreased EGFR levels in the normal-diet group, which is reversed in the high-cholesterol-diet group (Fig. 6c), indicating that doxorubicin-mediated downregulation of EGFR is dependent on cholesterol levels. We also demonstrated the effect of cholesterol on doxorubicin efficacy using another in vivo model, the multivulva phenotype model in C. elegans (Fig. 6e, f). This small nematode is frequently used to test the efficacy and toxicity of drugs, including doxorubicin [45]. In particular, C. elegans tumorigenesis models, including multivulva development (a form of hyperplasia) and germ cell tumors, have been used for several decades to understand signal transduction pathways in vivo $[46,47]$. Previously, we reported that the jgIs 25 strain displays a high incidence of the multivulva phenotype [23]. The jgIs 25 strain expresses chimeric LET-23/EGFR which contains the active kinase domain of human EGFR with T790M and L858R mutations. These mutations are found in human non-small cell lung cancer and convey resistance against EGFR tyrosine kinase inhibitors [48]. When the jgIs 25 stain was treated with doxorubicin, EGFRmediated multivulva formation was decreased by doxorubicin to a greater extent in the absence of cholesterol, but was also slightly decreased in the presence of cholesterol (Fig. 6e, f). Taken all together, our data suggest that the EGFR/Src/HMG-CR pathway is one of the mechanisms by which doxorubicin induces apoptosis and that levels of cholesterol are critical for anti-cancer activity of doxorubicin.

Cholesterol accumulation is a general feature of various cancers, including breast, prostate, and colorectal cancers [29]. Hypercholesterolemia enhances mammary tumor growth and metastasis in murine models that are fed with a high-cholesterol diet $[49,50]$. Recent epidemiologic data show that low serum cholesterol levels are associated with a decreased risk of developing aggressive or advanced prostate cancer, suggesting a role for cholesterol in aggressive prostate cancer development [51]. Statins are HMG-CR inhibitors that lower cholesterol levels and are widely prescribed to treat cardiovascular diseases. In addition, although the effect of HMG-CR inhibitors (statins) is somewhat controversial in breast cancer [52], several studies reported a reduced occurrence of malignancy in 
patients taking statins [53, 54]. HMG-CR expression tends to be inversely correlated with low overall survival and is higher in cancer tissues than in normal tissues (Suppl. Figure 9 and Suppl. Figure 10). Although it remains to be elucidated whether serum cholesterol levels and/or HMG$\mathrm{CR}$ expression levels in cancer tissue is inversely correlated with doxorubicin efficacy in cancer patients, our data strongly suggest that lowering cholesterol, by either use of HMG-CR inhibitors or by diet control, could be a critical strategy to enhance doxorubicin efficacy. Increased doxorubicin efficacy would lower the required dose of doxorubicin and thus be beneficial for reducing dose-dependent cardiotoxicity.

Acknowledgements This work was supported by a research grant from the National Cancer Center, Republic of Korea (NCC-1510090) and National Research Foundation (NRF) grant funded by Korea government (NRF-2011-0016025).

\section{Compliance with ethical standards}

Conflict of interest The authors declare that they have no conflict of interest.

Publisher's note: Springer Nature remains neutral with regard to jurisdictional claims in published maps and institutional affiliations.

\section{References}

1. Doroshow JH. Doxorubicin-induced cardiac toxicity. N Engl J Med. 1991;324:843-5.

2. Riganti C, Doublier S, Costamagna C, Aldieri E, Pescarmona G, Ghigo D, et al. Activation of nuclear factor-kappa B pathway by simvastatin and RhoA silencing increases doxorubicin cytotoxicity in human colon cancer HT29 cells. Mol Pharmacol. 2008;74:476-84.

3. Werner M, Sacher J, Hohenegger M. Mutual amplification of apoptosis by statin-induced mitochondrial stress and doxorubicin toxicity in human rhabdomyosarcoma cells. Br J Pharmacol. 2004;143:715-24.

4. Kozar K, Kaminski R, Legat M, Kopec M, Nowis D, Skierski JS, et al. Cerivastatin demonstrates enhanced antitumor activity against human breast cancer cell lines when used in combination with doxorubicin or cisplatin. Int J Oncol. 2004;24:1149-57.

5. Martirosyan A, Clendening JW, Goard CA, Penn LZ. Lovastatin induces apoptosis of ovarian cancer cells and synergizes with doxorubicin: potential therapeutic relevance. BMC Cancer. 2010;10:103.

6. Fromigue O, Hamidouche Z, Marie PJ. Statin-induced inhibition of 3-hydroxy-3-methyl glutaryl coenzyme a reductase sensitizes human osteosarcoma cells to anticancer drugs. J Pharmacol Exp Ther. 2008;325:595-600.

7. Goldstein JL, Brown MS. Regulation of the mevalonate pathway. Nature. 1990;343:425-30.

8. Roudier E, Mistafa O, Stenius U. Statins induce mammalian target of rapamycin (mTOR)-mediated inhibition of Akt signaling and sensitize p53-deficient cells to cytostatic drugs. Mol Cancer Ther. 2006;5:2706-15.

9. Kawata S, Yamasaki E, Nagase T, Inui Y, Ito N, Matsuda Y, et al. Effect of pravastatin on survival in patients with advanced hepatocellular carcinoma. A randomized controlled trial. Br J Cancer. 2001;84:886-91.

10. Lopez-Aguilar E, Sepulveda-Vildosola AC, Betanzos-Cabrera Y, Rocha-Moreno YG, Gascón-Lastiri G, Rivera-Márquez H, et al. Phase II study of metronomic chemotherapy with thalidomide, carboplatin-vincristine-fluvastatin in the treatment of brain stem tumors in children. Arch Med Res. 2008;39:655-62.

11. Silvente-Poirot S, Poirot M. Cancer. Cholesterol and cancer, in the balance. Science. 2014;343:1445-6.

12. Park EK, Lee EJ, Lee SH, Koo KH, Sung JY, Hwang EH, et al. Induction of apoptosis by the ginsenoside $\mathrm{Rh} 2$ by internalization of lipid rafts and caveolae and inactivation of Akt. Br J Pharmacol. 2010;160:1212-23.

13. Li YC, Park MJ, Ye SK, Kim CW, Kim YN. Elevated levels of cholesterol-rich lipid rafts in cancer cells are correlated with apoptosis sensitivity induced by cholesterol-depleting agents. Am J Pathol. 2006;168:1107-18. quiz404-5

14. Zhuang L, Lin J, Lu ML, Solomon KR, Freeman MR. Cholesterol-rich lipid rafts mediate akt-regulated survival in prostate cancer cells. Cancer Res. 2002;62:2227-31.

15. Freeman MR, Solomon KR. Cholesterol and prostate cancer. J Cell Biochem. 2004;91:54-69.

16. Lee SH, Koo KH, Park JW, Kim HJ, Ye SK, Park JB, et al. HIF-1 is induced via EGFR activation and mediates resistance to anoikislike cell death under lipid rafts/caveolae-disrupting stress. Carcinogenesis. 2009;30:1997-2004

17. Alikhani N, Ferguson RD, Novosyadlyy R, Gallagher EJ, Scheinman EJ, Yakar S, et al. Mammary tumor growth and pulmonary metastasis are enhanced in a hyperlipidemic mouse model. Oncogene. 2012;32:961-7.

18. Platz EA, Leitzmann MF, Visvanathan K, Rimm EB, Stampfer MJ, Willett WC, et al. Statin drugs and risk of advanced prostate cancer. J Natl Cancer Inst. 2006;98:1819-25.

19. Sun LM, Lin MC, Lin CL, Chang SN, Liang JA, Lin IC, et al. Statin use reduces prostate cancer all-cause mortality: a Nationwide Population-Based Cohort Study. Medicine. 2015;94:e1644.

20. Lacher SM, Bruttger J, Kalt B, Berthelet J, Rajalingam K, Wörtge $\mathrm{S}$, et al. HMG-CoA reductase promotes protein prenylation and therefore is indispensible for T-cell survival. Cell Death Dis. 2017;8:e2824.

21. Yun UJ, Lee JH, Koo KH, Ye SK, Kim SY, Lee CH, et al. Lipid raft modulation by $\mathrm{Rp} 1$ reverses multidrug resistance via inactivating MDR-1 and Src inhibition. Biochem Pharmacol. 2013;85:1441-53.

22. Ambery AG, Tackett L, Penque BA, Brozinick JT, Elmendorf JS. Exercise training prevents skeletal muscle plasma membrane cholesterol accumulation, cortical actin filament loss, and insulin resistance in C57BL/6J mice fed a western-style high-fat diet. Physiol Rep. 2017;5:e13363.

23. Bae YK, Sung JY, Kim YN, Kim S, Hong KM, Kim HT, et al. An in vivo $C$. elegans model system for screening EGFR-inhibiting anti-cancer drugs. PLoS ONE. 2012;7:e42441.

24. Brenner S. The genetics of Caenorhabditis elegans. Genetics. 1974;77:71-94.

25. Park EK, Park MJ, Lee SH, Li YC, Kim J, Lee JS, et al. Cholesterol depletion induces anoikis-like apoptosis via FAK downregulation and caveolae internalization. $\mathrm{J}$ Pathol. 2009;218:337-49.

26. Horton JD, Goldstein JL, Brown MS. SREBPs: activators of the complete program of cholesterol and fatty acid synthesis in the liver. J Clin Invest. 2002;109:1125-31.

27. Zhao TT, Le Francois BG, Goss G, Ding K, Bradbury PA, Dimitroulakos J. Lovastatin inhibits EGFR dimerization and AKT activation in squamous cell carcinoma cells: potential regulation by targeting rho proteins. Oncogene. 2010;29:4682-92. 
28. Lee JC, Park BK, Choung S, Kim JM, Joung KH, Lee JH, et al. Amelioration of hypercholesterolemia by an EGFR tyrosine kinase inhibitor in mice with liver-specific knockout of Mig-6. PLoS ONE. 2014;9:e114782.

29. Murai T. Cholesterol lowering: role in cancer prevention and treatment. Biol Chem. 2015;396:1-11.

30. Chitwood DJ, Lusby WR, Lozano R, Thompson MJ, Svoboda JA. Novel nuclear methylation of sterols by the nematode Caenorhabditis elegans. Steroids. 1983;42:311-9.

31. Vejpongsa P, Yeh ET. Prevention of anthracycline-induced cardiotoxicity: challenges and opportunities. J Am Coll Cardiol. 2014;64:938-45.

32. Simons K, Ikonen E. Functional rafts in cell membranes. Nature. 1997;387:569-72.

33. Kuzu OF, Noory MA, Robertson GP. The role of cholesterol in cancer. Cancer Res. 2016;76:2063-70.

34. Asslan R, Pradines A, Pratx C, Allal C, Favre G, Le Gaillard F. Epidermal growth factor stimulates 3-hydroxy-3-methylglutaryl-coenzyme A reductase expression via the ErbB-2 pathway in human breast adenocarcinoma cells. Biochem Biophys Res Commun. 1999;260:699-706.

35. Zhuang L, Kim J, Adam RM, Solomon KR, Freeman MR. Cholesterol targeting alters lipid raft composition and cell survival in prostate cancer cells and xenografts. J Clin Invest. 2005;115: 959-68.

36. Patra SK. Dissecting lipid raft facilitated cell signaling pathways in cancer. Biochim Biophys Acta. 2008;1785:182-206.

37. Montero J, Morales A, Llacuna L, Lluis JM, Terrones O, Basañez G, et al. Mitochondrial cholesterol contributes to chemotherapy resistance in hepatocellular carcinoma. Cancer Res. 2008;68:5246-56.

38. Dominguez-Perez M, Simoni-Nieves A, Rosales P, NuñoLámbarri N, Rosas-Lemus M, Souza V, et al. Cholesterol burden in the liver induces mitochondrial dynamic changes and resistance to apoptosis. J Cell Physiol. 2018.

39. Garcia-Ruiz C, Mari M, Colell A, Morales A, Caballero F, Montero J, et al. Mitochondrial cholesterol in health and disease. Histol Histopathol. 2009;24:117-32.

40. Das B, Yeger H, Baruchel H, Freedman MH, Koren G, Baruchel $\mathrm{S}$. In vitro cytoprotective activity of squalene on a bone marrow versus neuroblastoma model of cisplatin-induced toxicity. implications in cancer chemotherapy. Eur J Cancer. 2003;39:2556-65.

41. Haskins JW, Zhang S, Means RE, Kelleher JK, Cline GW, Canfrán-Duque A, et al. Neuregulin-activated ERBB4 induces the SREBP-2 cholesterol biosynthetic pathway and increases lowdensity lipoprotein uptake. Sci Signal. 2015;8:ra111.

42. Frame MC. Src in cancer: deregulation and consequences for cell behaviour. Biochim Biophys Acta. 2002;1602:114-30.
43. Ortiz C, Caja L, Sancho P, Bertran E, Fabregat I. Inhibition of the EGF receptor blocks autocrine growth and increases the cytotoxic effects of doxorubicin in rat hepatoma cells: role of reactive oxygen species production and glutathione depletion. Biochem Pharmacol. 2008;75:1935-45.

44. Buchholz TA, Tu X, Ang KK, Esteva FJ, Kuerer HM, Pusztai L, et al. Epidermal growth factor receptor expression correlates with poor survival in patients who have breast carcinoma treated with doxorubicin-based neoadjuvant chemotherapy. Cancer. 2005;104: 676-81.

45. Papaluca A, Ramotar D. A novel approach using C. elegans DNA damage-induced apoptosis to characterize the dynamics of uptake transporters for therapeutic drug discoveries. Sci Rep. 2016;6: 36026.

46. Saffer AM, Kim DH, van Oudenaarden A, Horvitz HR. The Caenorhabditis elegans synthetic multivulva genes prevent ras pathway activation by tightly repressing global ectopic expression of lin-3 EGF. PLoS Genet. 2011;7:e1002418.

47. Subramaniam K, Seydoux G. Dedifferentiation of primary spermatocytes into germ cell tumors in C. elegans lacking the pumiliolike protein PUF-8. Curr Biol. 2003;13:134-9.

48. Kobayashi S, Boggon TJ, Dayaram T, Jänne PA, Kocher $\mathrm{O}$, Meyerson M, et al. EGFR mutation and resistance of nonsmall-cell lung cancer to gefitinib. N Engl J Med. 2005;352: 786-92.

49. Pelton K, Coticchia CM, Curatolo AS, Schaffner CP4, Zurakowski D5, Solomon KR, et al. Hypercholesterolemia induces angiogenesis and accelerates growth of breast tumors in vivo. Am J Pathol. 2014;184:2099-110.

50. Alikhani N, Ferguson RD, Novosyadlyy R, Gallagher EJ, Scheinman EJ, Yakar S, et al. Mammary tumor growth and pulmonary metastasis are enhanced in a hyperlipidemic mouse model. Oncogene. 2013;32:961-7.

51. Lee BH, Taylor MG, Robinet P, Smith JD, Schweitzer J, Sehayek E, et al. Dysregulation of cholesterol homeostasis in human prostate cancer through loss of ABCA1. Cancer Res. 2013;73: 1211-8.

52. Eliassen AH, Colditz GA, Rosner B, Willett WC, Hankinson SE. Serum lipids, lipid-lowering drugs, and the risk of breast cancer. Arch Intern Med. 2005;165:2264-71.

53. Jacobs EJ, Rodriguez C, Bain EB, Wang Y, Thun MJ, Calle EE. Cholesterol-lowering drugs and advanced prostate cancer incidence in a large U.S. cohort. Cancer Epidemiol Biomark Prev. 2007;16:2213-7.

54. Murtola TJ, Visvanathan K, Artama M, Vainio H, Pukkala E. Statin use and breast cancer survival: a nationwide cohort study from Finland. PLoS ONE. 2014;9:e110231. 